\title{
Emerging therapeutic opportunities for integrin inhibitors
}

\author{
R. J. Slack', S. J. F. Macdonald $\mathbb{1}^{2}$, J. A. Roper $\mathbb{1}^{1}$, R. G. Jenkins $\mathbb{1}^{3}$ \\ and R. J. D. Hatley $\mathbb{1}^{2 凶}$
}

Abstract | Integrins are cell adhesion and signalling proteins crucial to a wide range of biological functions. Effective marketed treatments have successfully targeted integrins allb $\beta 3, \alpha 4 \beta 7 / \alpha 4 \beta 1$ and $\alpha \mathrm{L} \beta 2$ for cardiovascular diseases, inflammatory bowel disease/multiple sclerosis and dry eye disease, respectively. Yet, clinical development of others, notably within the RGD-binding subfamily of av integrins, including av $\beta 3$, have faced significant challenges in the fields of cancer, ophthalmology and osteoporosis. New inhibitors of the related integrins $\alpha v \beta 6$ and $\alpha v \beta 1$ have recently come to the fore and are being investigated clinically for the treatment of fibrotic diseases, including idiopathic pulmonary fibrosis and nonalcoholic steatohepatitis. The design of integrin drugs may now be at a turning point, with opportunities to learn from previous clinical trials, to explore new modalities and to incorporate new findings in pharmacological and structural biology. This Review intertwines research from biological, clinical and medicinal chemistry disciplines to discuss historical and current RGD-binding integrin drug discovery, with an emphasis on small-molecule inhibitors of the av integrins.

Integrin proteins are ubiquitous, heterodimeric, transmembrane glycoprotein receptors that primarily act as signalling proteins in mammals ${ }^{1}$. Each consists of an $\alpha$-subunit and a $\beta$-subunit, of which there are 18 and 8 variants, respectively, creating the 24 known heterodimers (FIG. 1). The $\alpha$ - and $\beta$-subunits are bound in a noncovalent complex with the ligand-binding site at the interface. Integrins act as adhesion receptors, with the unusual ability to signal in both directions across the plasma membrane ${ }^{2}$. These events are called 'inside-out' signalling ${ }^{3}$ and 'outside-in' signalling ${ }^{4}$, resulting either from binding to extracellular ligands or from interacting with the cytoskeleton via the integrin intracellular domains. Integrins can therefore enable human cells to respond to changes in the extracellular environment (via outside-in signalling) and can influence the extracellular environment itself (via inside-out signalling). Information from outside the cell is communicated intracellularly when the ligand binds to the receptor, resulting in changes in cell polarity, cytoskeletal structure, gene expression, cell survival and proliferation ${ }^{5}$. In the opposite direction, intracellular activators such as talin-1 (REF. ${ }^{6}$ ) bind to the cytoplasmic tail of the $\beta$-subunit, evoking a conformational change that shifts the integrin into a high-affinity state, which more readily binds to extracellular ligands and thus promotes cell migration and extracellular matrix (ECM) assembly and remodelling ${ }^{7}$.
The integrin proteins are classified into families that consist of receptors with related properties (FIG. 1). For example, all eight members of the RGD-binding family of integrins recognize the amino acid binding motif Arg-Gly-Asp (RGD) in their endogenous ligands. The related integrins $\alpha 4 \beta 7$ and $\alpha 4 \beta 1$ are therapeutic targets that are expressed on leukocytes and also recognize short peptide sequences, one of which is Leu-Asp-Val $(\mathrm{LDV})^{8,9}$. In addition, families of integrins that bind to either collagen ${ }^{10}$ or laminin ${ }^{11}$ have wide-ranging roles in disease, but to date have not been extensively targeted ${ }^{12,13}$.

The inhibition of integrins has led to several marketed drugs, and many others are being investigated preclinically in both academic and industry settings. Since 2015, there have been at least 130 clinical trials of integrin-targeted therapies (https://www.clinicaltrials.gov/.clinicaltrials.gov and https://www.clinicaltrialsregister.eu/ctr-search/search using search term "integrin"). (This number is an estimation because there are clinical trials with integrin molecules that are not returned with this search term. Databases interrogated December 2020.) In total, six integrin inhibitor drugs, targeting four integrins ( $\alpha \operatorname{IIb} \beta 3$ (also known as glycoprotein IIb/IIIa), $\alpha 4 \beta 7, \alpha 4 \beta 1$ and $\alpha \mathrm{L} \beta 2$ ), have been marketed (TABLE 1). Three of these drugs are antibodies and three are small molecules, but none is delivered by the oral route - contributing factors for the lack of 
orally available small molecules include the polar pharmacophore in those molecules coupled with complex pharmacology for the target pathway ${ }^{14}$. Intravenously administered inhibitors of the RGD-binding integrin $\alpha \operatorname{IIb} \beta 3$ were some of the first developed, exemplified by two small molecules, tirofiban (Aggrastat) and eptifibatide (Integrilin), alongside the antibody abciximab (ReoPro). All three therapies are prescribed for acute coronary syndrome and for the treatment of thrombotic cardiovascular events ${ }^{15}$ (BOX 1; TABLE 1). Additionally, drug discovery programmes centred on the integrin $\alpha \mathrm{L} \beta 2$ (which is expressed on leukocytes) delivered a marketed small molecule, lifitegrast, for the topical treatment of dry eye disease ${ }^{16}$. Inhibitors of $\alpha \mathrm{L} \beta 2$ have also been investigated for autoimmune diseases and inflammatory disorders ${ }^{17}$.

The remaining marketed integrin drugs, vedolizumab (Entyvio) and natalizumab (Tysabri), are
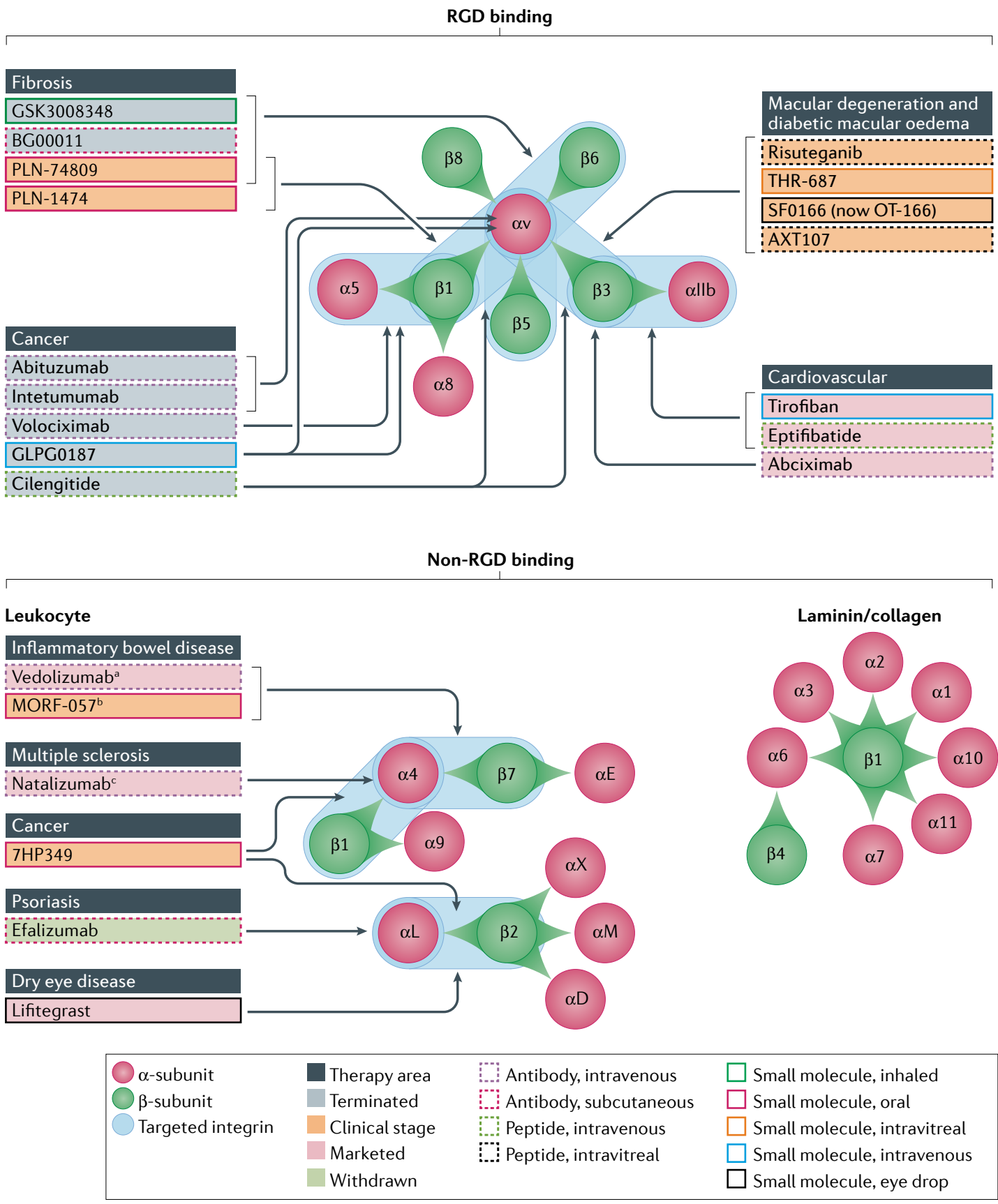

Fig. 1 | The integrin family and targeted therapies. All 24 distinct integrin heterodimers, formed from one $\alpha$-subunit and one $\beta$-subunit, are represented and grouped according to their broad classification by cognate ligand or cellular expression. Therapeutically targeted integrins are highlighted in blue along with the therapeutic areas that are of current interest. Additionally, a select number of therapies in development, and marketed or terminated drugs and their modalities, are shown. Arrows are intended to demonstrate which integrin targets are thought to be key and their purpose is not to capture all known integrin activities. See Tables for additional information. 'Approved for ulcerative colitis and Crohn's

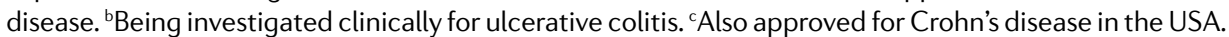


Table 1 | Approved integrin-targeting drugs

\begin{tabular}{|c|c|c|c|c|c|}
\hline $\begin{array}{l}\text { Generic name } \\
\text { (brand name; } \\
\text { manufacturer) }\end{array}$ & $\begin{array}{l}\text { Chemotype; route } \\
\text { of administration }\end{array}$ & Target; mechanism of action & Indication & Dose $^{185}$ & $\begin{array}{l}\text { Date of } \\
\text { regulatory } \\
\text { approval }\end{array}$ \\
\hline $\begin{array}{l}\text { Lifitegrast } \\
\text { (Xiidra; } \\
\text { Novartis) }\end{array}$ & $\begin{array}{l}\text { Small molecule; } \\
\text { topical }\end{array}$ & $\begin{array}{l}\alpha \mathrm{L} \beta 2 \text { (LFA- } 1 \text { ) antagonist; prevents } \\
\text { lymphocyte adhesion, thereby } \\
\text { reducing T cell-mediated } \\
\text { inflammation }\end{array}$ & Dry eye disease & $\begin{array}{l}1 \text { drop in each eye } \\
\text { every } 12 \mathrm{~h}\end{array}$ & July 2016 \\
\hline $\begin{array}{l}\text { Vedolizumab } \\
\text { (Entyvio; } \\
\text { Takeda) }\end{array}$ & $\begin{array}{l}\text { Biologic (humanized } \\
\text { mAb); i.v. infusion }\end{array}$ & $\begin{array}{l}\text { a } 4 \beta 7 \text { antagonist; inhibits binding } \\
\text { to MADCAM1, thereby preventing } \\
\text { T cells from homing to the gut }\end{array}$ & $\begin{array}{l}\text { Ulcerative colitis } \\
\text { and Crohn's disease }\end{array}$ & $\begin{array}{l}300 \mathrm{mg} \text { infused over } \\
30 \text { min at weeks } 0,2,6 \\
\text { and every } 8 \text { weeks } \\
\text { thereafter }\end{array}$ & May 2014 \\
\hline $\begin{array}{l}\text { Natalizumab } \\
\text { (Tysabri; } \\
\text { Biogen) }\end{array}$ & $\begin{array}{l}\text { Biologic (humanized } \\
\text { mAb); i.v. infusion }\end{array}$ & $\begin{array}{l}\text { Pan- } \alpha 4 \text { antagonist; inhibits ligand } \\
\text { binding to } \alpha 4 \beta 7 \text { and } \alpha 4 \beta 1 \text {, thus } \\
\text { reducing homing of T cells to the } \\
\text { gut (in Crohn's disease) and across } \\
\text { the blood-brain barrier (in multiple } \\
\text { sclerosis) }\end{array}$ & $\begin{array}{l}\text { Multiple sclerosis } \\
\text { and Crohn's disease }\end{array}$ & $\begin{array}{l}300 \mathrm{mg} \text { infused over } \\
1 \text { h every } 4 \text { weeks }\end{array}$ & $\begin{array}{l}\text { November } \\
2004\end{array}$ \\
\hline $\begin{array}{l}\text { Efalizumab } \\
\text { (Raptiva; } \\
\text { Genentech/ } \\
\text { Merck Serono) }\end{array}$ & $\begin{array}{l}\text { Biologic (humanized } \\
\text { mAb); s.c. injection }\end{array}$ & $\begin{array}{l}\alpha \mathrm{L} \text { antagonist; targets lymphocyte- } \\
\text { specific } \alpha \mathrm{L} \beta 2 \text {, preventing } \\
\text { lymphocyte activation and migration }\end{array}$ & Plaque psoriasis & $\begin{array}{l}0.7 \mathrm{mg} \mathrm{kg}^{-1} \text { followed } \\
\text { by } 1 \mathrm{mg} \mathrm{kg}^{-1} \text { weekly }\end{array}$ & $\begin{array}{l}\text { October } 2003 \\
\text { (withdrawn } \\
\text { 2009) }\end{array}$ \\
\hline $\begin{array}{l}\text { Tirofiban } \\
\text { (Aggrastat; } \\
\text { Medicure \& } \\
\text { Correvio) }\end{array}$ & $\begin{array}{l}\text { Small molecule; } \\
\text { i.v. infusion }\end{array}$ & $\begin{array}{l}\text { allb } \beta 3 \text { antagonist, RGD mimetic; } \\
\text { prevents platelet aggregation by } \\
\text { inhibiting binding to fibrinogen }\end{array}$ & $\begin{array}{l}\text { Acute coronary syndrome } \\
\text { and thrombotic } \\
\text { cardiovascular events }\end{array}$ & $\begin{array}{l}25 \mathrm{mg} \mathrm{kg}^{-1} \text { followed } \\
\text { by } 0.15 \mathrm{mg} \mathrm{kg}^{-1} \mathrm{~min}^{-1} \\
\text { for } 18 \mathrm{~h}\end{array}$ & August 1998 \\
\hline $\begin{array}{l}\text { Eptifibatide } \\
\text { (Integrilin; } \\
\text { Takeda, GSK, } \\
\text { Merck) }\end{array}$ & $\begin{array}{l}\text { Small molecule } \\
\text { (heptapeptide); } \\
\text { i.v. injection }\end{array}$ & $\begin{array}{l}\text { allb } \beta 3 \text { antagonist, RGD mimetic; } \\
\text { prevents platelet aggregation by } \\
\text { inhibiting binding to fibrinogen }\end{array}$ & $\begin{array}{l}\text { Acute coronary syndrome } \\
\text { and thrombotic } \\
\text { cardiovascular events }\end{array}$ & $\begin{array}{l}180 \mathrm{mg} \mathrm{kg}^{-1} \text { followed } \\
\text { by } 2 \mathrm{mg} \mathrm{kg}^{-1} \mathrm{~min}^{-1} \text { for } \\
\text { up to } 72 \mathrm{~h}\end{array}$ & May 1998 \\
\hline $\begin{array}{l}\text { Abciximab } \\
\text { (ReoPro; } \\
\text { Centocor, Inc./ } \\
\text { Eli Lilly/Janssen } \\
\text { Biotech, Inc.) }\end{array}$ & $\begin{array}{l}\text { Biologic } \\
\text { (antigen-binding } \\
\text { fragment); } \\
\text { i.v. injection }\end{array}$ & $\begin{array}{l}\text { Pan- } \beta 3 \text { antagonist; inhibits binding } \\
\text { of integrin allb } \beta 3 \text { to fibronectin, thus } \\
\text { preventing platelet aggregation }\end{array}$ & $\begin{array}{l}\text { Acute coronary syndrome } \\
\text { and thrombotic } \\
\text { cardiovascular events }\end{array}$ & $\begin{array}{l}0.25 \mathrm{mg} \mathrm{kg}^{-1}, \text { followed } \\
\text { by } 10 \mathrm{mg} \mathrm{kg}^{-1} \mathrm{~min}^{-1} \\
\text { for } 12 \mathrm{~h}\end{array}$ & $\begin{array}{l}\text { December } \\
1994\end{array}$ \\
\hline
\end{tabular}

Successful drugs gaining regulatory approval are tabulated in order of approval date, with most recent first. GSK, GlaxoSmithKline; i.v., intravenous; mAb, monoclonal antibody; MADCAM1, mucosal addressin cell adhesion molecule 1; RGD, Arg-Gly-Asp; s.c., subcutaneous.

antibodies that act principally on the leukocyte integrins $\alpha 4 \beta 7$ and $\alpha 4 \beta 1$ and are used for treating ulcerative colitis, Crohn's disease ${ }^{18}$ and multiple sclerosis ${ }^{19}$. Combined sales of these two molecules have reached more than \$US4 billion per year ${ }^{20,21}$, underlining the impact of integrin inhibitors in treating disease. However, this class of molecules suffered a setback in 2009 when efalizumab, which targeted $\alpha \mathrm{L}$ integrins (these are also expressed predominantly on leukocytes), was withdrawn from the market because of multiple cases of progressive multifocal leukoencephalopathy (PML), believed to be associated with inhibition of $\alpha 4$-containing integrins and $\alpha \mathrm{L} \beta 2$ $\left(\right.$ REF. $^{22}$ ) (BOX 2). Similarly, natalizumab was withdrawn from the market in early 2005 after its use was associated with PML in patients with multiple sclerosis; natalizumab returned the following year with a black box warning about the increased risk of PML, after a detailed review of all clinical trial data. These high-value biological targets continue to be investigated clinically with the risk of PML in mind. Indeed, two orally delivered antagonists of $\alpha 4 \beta 7$ are in clinical trials: a small molecule from Morphic Therapeutics (which is in phase I) and a peptide from Protagonist Therapeutics (which is in phase II) (TABLE 2).

Excitingly, new molecules that target av-containing integrins are now entering clinical trials for fibrotic diseases, including idiopathic pulmonary fibrosis (IPF) and nonalcoholic steatohepatitis (NASH), which have high and increasing ${ }^{23,24}$ unmet medical need. Because integrin proteins are pivotal to numerous biological pathways ${ }^{25}$ and they bind to a variety of endogenous ligands, inhibition of a single integrin or integrin family could treat a range of diseases ${ }^{26}$, such as multiple fibrotic diseases or multiple types of cancer.

It is therefore timely to discuss the progress made in drug discovery for the RGD-binding integrins, mainly the av integrin subfamily, as detailed in this Review. Many of the lessons learned from this class of molecules are also pertinent to drug discovery and integrins in general. We discuss the different modalities adopted in integrin drug discovery, alongside their mechanisms, and diseases that might be treated by inhibition of these integrins. We also assess the factors to consider in integrin inhibitor drug design - the unusual physicochemical properties, how to achieve selectivity, the optimal modes of administration and the pharmacology. The latest developments will be discussed alongside the learnings from past programmes and clinical terminations to provide insight on the progress made to identify new, safe and effective treatments. We conclude with a summary of the key challenges and prospects for therapies that target integrins. 


\section{Box 1 | Therapeutic successes targeting blood cell-specific integrins}

The restricted expression of specific integrins on blood cells that mediate adhesion and migration has led to a longstanding interest in targeting integrins in cardiovascular and autoimmune diseases. Loss of functional integrin allb $\beta 3$ in patients with the clotting defect Glanzmann thrombasthenia highlighted this receptor as a potential target to treat cardiovascular conditions that involve abnormal clotting. Subsequent work identified the specific RGD motif in fibrinogen that binds to allb $\beta 3$ (REF. ${ }^{199}$ ), which initiated early target-led drug discovery programmes. These efforts led to the first approved integrin inhibitor, abciximab (ReoPro), a humanized antibody fragment with antagonist activity towards $\beta 3$. Following the success of abciximab, two other allb $\beta 3$ inhibitors were approved, one peptide (eptifibatide) and one small molecule (tirofiban). All these drugs achieve their antithrombotic effects by preventing allb $\beta 3$ on activated platelets from binding to fibrinogen, thereby preventing platelet aggregation. Expectations for the utility of this class of therapies as antithrombotics was high because they inhibit coagulation irrespective of which pathway or pathways led to platelet activation. However, this enthusiasm waned when several orally available allb $\beta 3$ ligand mimetics were found to agonize allb $\beta 3$ when binding, thereby causing paradoxical platelet activation that potentially led to the increased cardiovascular mortality observed in clinical trials ${ }^{200}$. Lack of efficacy, together with low rates of receptor occupancy at trough concentrations, meant that platelet aggregation became a risk, halting the progression of oral compounds. Although these drugs are still useful in the acute treatment of patients receiving percutaneous angioplasty, this subclass of approved antiplatelet drugs has been superseded by other rapidly acting antithrombotics. However, recently, an allb $\beta 3$-binding small molecule, RUC-4 (REF. ${ }^{63}$ ) (the structure is shown as $\mathbf{1 2}$ in FIG. 2), that does not induce platelet-activating conformational changes in allb $\beta 3$ has shown some promise in early-stage clinical trials (ClinicalTrials.gov identifier: NCT03844191) ${ }^{65}$. This molecule is compatible with subcutaneous injection (so it can be administered before hospital admission), and competes with the magnesium ions required for conformational change, thus locking allb $\beta 3$ in its inactive state. This recent development seeks to overcome the major prevailing drawbacks associated with oral antithrombotics and currently approved allb $\beta 3$ inhibitors and reignites interest in allb $\beta 3$ inhibitors for the treatment of cardiovascular disease.
(Oxurion/Galapagos), which is currently in phase I trials for DME. JSM-6427 (Takeda, proposed structure shown in $\mathbf{3}$ ) is a peptidic small molecule that has been evaluated preclinically for treating ocular neovascular diseases ${ }^{35}$ and progressed to phase I clinical trials for AMD. However, no data have been reported since 2010. Most recently, a 20-mer synthetic peptide that targets both $\alpha v \beta 3$ and $\alpha 5 \beta 1$ (AXT-107, developed by AsclepiX Therapeutics), derived from the non-collagenous domain of collagen IV, has entered clinical trials for treating retinal vascular diseases ${ }^{36,37}$.

Although molecules that target av $\beta 3$ integrins generally have an acceptable safety profile (TABLE 3), interest in using them to tackle cancer has waned, mainly owing to lack of efficacy. Broad reasons for failure may encompass several factors, such as redundancy, promiscuity and compensation mechanisms $s^{38}$. The most studied av $\beta 3$ inhibitor molecule and furthest progressed is the cyclic peptide, cilengitide (Merck KGaA, 1), which also inhibits av $\beta 5$ and $\alpha 5 \beta 1$ and has been assessed in approximately 30 different clinical trials for cancer. Ultimately, however, cilengitide fell short in phase III trials owing to a lack of efficacy against glioblastomas, with no improvement in overall survival ${ }^{39,40}$. Antibodies that target av $\beta 3$, such as etaracizumab (MEDI-522; Abergrin) also advanced to clinical trials for several diseases, including cancer $^{41}$, but progression has halted. GLPG0187 (7), a broad-spectrum av inhibitor, also failed to show signs of efficacy in a phase Ib trial in patients with solid tumours, again, despite being well tolerated ${ }^{42}$.

Meanwhile, alternative approaches to av $\beta 3$ inhibition are offering greater promise for treating the same or similar diseases: there are numerous promising therapies for treating glioblastomas ${ }^{43}$, cathepsin $\mathrm{K}$ inhibitors could be useful in osteoporosis ${ }^{44}$ and agents targeting vascular endothelial growth factor A (VEGFA), such as ranibizumab, are already available for treating $\mathrm{AMD}^{45}$. Any new drug discovery programme focused on the av $\beta 3$ integrin will therefore require convincing target validation and demonstrable evidence that preclinical models are predictive of effects in the clinic. Academic research on the role of $\alpha v \beta 3$ in cancer and other areas continues, aided by several high-quality tools that are available to test integrin-mediated mechanisms in new disease models to potentially deliver more effective therapies.

In recent years, $\alpha v \beta 6$ and the well-established target $\alpha 4 \beta 7$ have attracted substantial interest as therapeutic targets. Several new inhibitors of the $\alpha v \beta 6$ and/or av $\beta 1$ integrins (most of which are small molecules) have progressed to clinical trials in the past 5 years, and $\alpha 4 \beta 7$-directed therapies (mostly antibodies) have advanced to late-stage clinical trials. The change in focus from $\alpha v \beta 3$ to $\alpha v \beta 6$ also switches the focus of downstream effector pathways from angiogenesis to modulation or inhibition of the transforming growth factor $\beta$ (TGF $\beta$ ) pathway (BOX 3). The increased interest in $\alpha 4 \beta 7$ has presumably come from the clear benefit to patients from prescribed drugs, such as natalizumab, and the need for alternative therapies after several terminated clinical trials and withdrawals, specifically in ulcerative colitis and multiple sclerosis. 


\section{Modalities and mechanisms}

Integrins can be targeted with a range of mechanisms designed to activate (as agonists) or inactivate (as silent antagonists or inhibitors) the integrin complex, inhibit a secondary biological process initiated by the integrin (as functional antagonists), deliver a cytotoxic drug (as a drug conjugate) in a cell-specific manner or direct chimeric antigen receptor $\mathrm{T}$ (CAR $\mathrm{T}$ ) cells for immunotherapy ${ }^{46-48}$. The majority of integrin drug discovery initiatives have set out to target the orthosteric binding sites (endogenous ligand-binding sites) on integrins, which are formed when the $\alpha$ - and $\beta$-subunits bind to each other in a noncovalent complex. However, several drug discovery programmes that targeted the orthosteric site have not been successful, which highlights the potential risks of this approach. Some of the approved therapies exert their effects via allosteric interactions with the $\alpha$-subunits of the integrins they target; for example, natalizumab exclusively targets the $\alpha 4$-subunit of $\alpha 4 \beta 1$ at an allosteric site (REF. ${ }^{49}$ ) (TABLE 1).

Integrins can exist in an activated or inactivated state, in which they demonstrate high or low affinity for ligands,

\section{Box 2 | Targeting the $\alpha 4$ integrins in multiple sclerosis and inflammatory} bowel disease

The leukocyte-specific integrins - $\alpha \mathrm{L} \beta 2, \alpha M \beta 2, \alpha D \beta 2, \alpha E \beta 7$ and $\alpha 4 \beta 7$ - remain attractive targets to modulate immune cell-mediated diseases as each of them has a key role in immune cell function. Additionally, although it is not exclusively expressed in leukocytes, $\alpha 4 \beta 1$ is required for the adhesion of immune cells to vascular cell adhesion molecule 1 (VCAM1), which is expressed on inflamed endothelium; this interaction is important for the infiltration of immune cells into the central nervous system (CNS). Blockade of $\alpha 4$ prevented paralysis in a T cell-induced rat model of multiple sclerosis, and blockade of $\alpha 4 \beta 1$ specifically inhibited binding of immune cells to inflamed brain vessels ${ }^{201}$. This study provided the rationale for targeting $\alpha 4 \beta 1$ in immune-mediated CNS diseases. Similarly, blocking the binding of $\alpha 4 \beta 7$ (the predominant leukocyte gut-homing receptor) to mucosal addressin cell adhesion molecule 1 (MADCAM1) prevents inflammation known to cause irritable bowel syndrome (IBS).

The pan- $\alpha 4$ inhibitor natalizumab (Tysabri) reduces clinical relapses in patients with multiple sclerosis. Natalizumab also reduces the severity of Crohn's disease, a subtype of inflammatory bowel disease (IBD), and increases the likelihood of clinical remission. However, the $\alpha 4 \beta 7$-specific biologic vedolizumab (Entyvio; approved in 2014) has largely replaced natalizumab in IBD indications because vedolizumab is less likely than natalizumab to cause progressive multifocal leukoencephalopathy (PML) and can be delivered subcutaneously (which is more convenient than the intravenous dosing required for natalizumab). Recent phase II results in treating ulcerative colitis with abrilumab (AMG181), another $\alpha 4 \beta 7$-specific antibody, in around 350 patients (ClinicalTrials.gov identifier: NCT01694485) suggest that this compound induces remission and mucosal healing in patients with moderate to severe ulcerative colitis without any incidence of $\mathrm{PML}^{202}$. Phase III trials of AMJ300, an oral $\alpha 4$-inhibiting prodrug, are also underway in patients with ulcerative colitis. The active metabolite has the same mechanism of action as natalizumab and may cause PML at similar frequency to natalizumab, but AMJ 300 has a shorter half-life than natalizumab and could therefore be quickly removed from the patient's body if PML occurs ${ }^{203}$. AMJ300 has also shown some efficacy in rodent models of multiple sclerosis, but development has so far focused on IBD indications.

Drugs that target $\beta 7$, which affect both $\alpha E \beta 7$ binding to $E$-cadherin and $\alpha 4 \beta 7$ binding to MADCAM1, are actively being developed for IBD indications. Unlike pan- $\alpha 4$ inhibitors, these drugs do not inhibit $\alpha 4 \beta 1$, so they should have a low risk of causing PML, and have the additional benefits (and risks) of reducing lymphocyte retention in the gut via aE $\beta 7$ inhibition. One such subcutaneously administered antibody, etrolizumab, showed promise in phase II studies in ulcerative colitis ${ }^{204,205}$, but failed to meet its primary end point versus placebo as maintenance therapy in a phase III study ${ }^{192}$. Despite the success of anti-integrin therapies in treating IBD, they remain a third-line treatment behind corticosteroid and antitumour necrosis factor therapies. respectively ${ }^{50}$. Extracellular ligand binding to the orthosteric site induces intracellular signalling, but also shifts the integrin from a low-affinity to a high-affinity state ${ }^{7}$. Under normal physiological conditions, this enables cells to respond to changes in the extracellular environment, but this response can become exaggerated and unwanted under pathophysiological condition $s^{51}$. Therefore, an antagonist molecule designed to bind to an integrin and prevent an endogenous ligand from binding may also have a direct agonist effect on the integrin if it causes this shift in affinity. These effects have been observed for marketed $\alpha I I b \beta 3$ RGD mimetics such as eptifibatide ${ }^{52}$, which induced severe thrombocytopenia in a small group of patients ${ }^{53}$, a phenomenon that was particularly evident during clinical trials with oral inhibitors ${ }^{54,55}$. In a related observation, low concentrations of av $\beta 3$ integrin RGD mimetics stimulate, rather than inhibit, tumour growth and angiogenesis in preclinical models ${ }^{56,57}$. Agonist effects can therefore also occur at low receptor occupancy for multiple members of the integrin family, perhaps in a manner analogous to the two-state model of activation of another family of membrane-bound receptors, the G protein-coupled receptors ${ }^{58}$. Importantly, these agonist effects may have caused or contibuted to the clinical failure of cilengitide $(\mathbf{1})^{56}$. Paradoxically, however, low-dose activation of an integrin receptor may indeed have therapeutic potential: in preliminary studies with cilengitide at low doses, its pro-angiogenic effects enhanced the delivery and potency of the chemotherapy agent gemcitabine to tumours ${ }^{59}$.

In light of this potential issue, academic groups have used structure-guided design to identify silent small-molecule integrin antagonists. Initial research hypothesized that the limitations manifested by thrombocytopenia and/or increased bleeding times with $\alpha \mathrm{IIb} \beta 3$ inhibitors were partially because the inhibitors induced high-affinity conformations of the integrin ${ }^{60}$. Inhibitors that minimize the agonist effects by stabilizing the low-affinity conformation have been designed and identified. One of the first breakthroughs in this area came with the amine ligands RUC-1 (REF. ${ }^{61}$ ) and RUC-2 (REF. ${ }^{62}$ ), which are non-RGD mimetics that bind to the orthosteric site in $\alpha \operatorname{IIb} \beta 3$ and induce smaller conformational changes in the $\beta 3$-subunit than marketed agents do. This observation has been backed up preclinically with the next molecule in the series, RUC-4 (12), which has reduced bleeding and the appropriate pharmacokinetic properties required for an antithrombotic drug, and may therefore be effective in the clinical setting $^{63}$. RUC-4 is currently in a phase II clinical trial (NCT04284995) by CeleCor Therapeutics ${ }^{64}$ to assess the pharmacokinetic and pharmacodynamic properties of a single subcutaneous injection in patients with a myocardial infarction ${ }^{65}$. This is a promising approach, and applying this binding principle to other av-containing integrins could provide opportunities to develop new non-zwitterionic chemotypes that do not induce potentially undesired conformational states. To our knowledge, such molecules are still in preclinical development, but the results are eagerly anticipated ${ }^{66}$.

Another group, meanwhile, reported the first crystal structure of a mutant of fibronectin bound to $\alpha v \beta 3$ 
Table 2 | Selected clinical studies with pending data

\begin{tabular}{|c|c|c|c|c|c|c|}
\hline Generic name (sponsor) & Modality & $\begin{array}{l}\text { Delivery } \\
\text { route }\end{array}$ & $\begin{array}{l}\text { Primary } \\
\text { integrin target }\end{array}$ & Indication & $\begin{array}{l}\text { ClinicalTrials. } \\
\text { gov identifiers }\end{array}$ & $\begin{array}{l}\text { Study } \\
\text { status }^{\mathrm{a}}\end{array}$ \\
\hline IDL-2965 (Indalo Therapeutics) & Small molecule & Oral & $\alpha v \beta 1, \alpha v \beta 3, \alpha v \beta 6$ & $\mathrm{IPF}^{186}, \mathrm{NASH}^{187}$ & NCT03949530 & Terminated \\
\hline PLN-74809 (Pliant Therapeutics) 15 & Small molecule & Oral & $\alpha v \beta 6, \alpha v \beta 1$ & $\begin{array}{l}\text { IPF, primary sclerosing } \\
\text { cholangitis }\end{array}$ & $\begin{array}{l}\text { NCT04072315, } \\
\text { NCT04396756, } \\
\text { NCT04480840 }\end{array}$ & Recruiting \\
\hline PLN-1474 (Pliant Therapeutics) & Small molecule & Oral & $\alpha \vee \beta 1$ & $\begin{array}{l}\text { End-stage liver fibrosis } \\
\text { in NASH }\end{array}$ & Not available & Recruiting \\
\hline PN-943 (Protagonist Therapeutics) & Peptide & Oral & $\alpha 4 \beta 7$ & Ulcerative colitis & NCT04504383 & Recruiting \\
\hline $\begin{array}{l}\text { CAR-T therapy (The Sixth Affiliated } \\
\text { Hospital of Wenzhou Medical } \\
\text { University) }\end{array}$ & $\begin{array}{l}\text { Cell-based } \\
\text { therapy }\end{array}$ & i.v. & $\beta 7$ & $\begin{array}{l}\text { Relapsed/refractory } \\
\text { multiple myeloma }\end{array}$ & NCT03778346 & Recruiting \\
\hline 7HP349 (7 Hills Pharma) & Small molecule & Oral & $\alpha L \beta 2, \alpha 4 \beta 1$ & Solid tumours & NCT04508179 & Recruiting \\
\hline MORF-057 (Morphic Therapeutics) & Small molecule & Oral & $\alpha 4 \beta 7$ & Healthy volunteers & NCT04580745 & $\begin{array}{l}\text { Active, not } \\
\text { recruiting }\end{array}$ \\
\hline $\begin{array}{l}\text { JSM-6427 (Jerini AG \& Shire } \\
\text { Pharmaceuticals, now Takeda } \\
\text { Pharma) } 3\end{array}$ & Small molecule & Parenteral & $\begin{array}{l}\alpha 5 \beta 1 \text { (also binds } \\
\alpha v \beta 6 / 8)\end{array}$ & $\begin{array}{l}\text { Age-related macular } \\
\text { degeneration }\end{array}$ & NCT00536016 & Completed \\
\hline OS2966 (OncoSynergy) & $\mathrm{mAb}$ & $\begin{array}{l}\text { Intratumoural } \\
\text { infusion }\end{array}$ & $\beta 1$ & Glioma & NCT04608812 & Recruiting \\
\hline AXT-107 (AsclepiX Therapeutics) & Peptide & $\begin{array}{l}\text { Intravitreal } \\
\text { injection }\end{array}$ & $\alpha v \beta 3, \alpha 5 \beta 1$ & DME, nAMD & $\begin{array}{l}\text { NCT04697758, } \\
\text { NCT04746963 }\end{array}$ & Recruiting \\
\hline
\end{tabular}

Emerging integrin-targeting therapies that are currently in clinical trials, or that have been in clinical trials but have not published any findings. This table details novel potential drugs intended as disease therapy, rather than those with potential diagnostic or prognostic value. Studies that have a clinical trials identifiers (NCT numbers) are indicated, together with the associated study status according to the latest data from www.clinicaltrials.gov. Numbers in bold refer to the molecule structures shown in FIGS 2,3. DME, diabetic macular oedema; IPF, idiopathic pulmonary fibrosis; i.v., intravenous; mAb, monoclonal antibody; nAMD, neovascular age-related macular degeneration; NASH, nonalcoholic steatohepatitis. ${ }^{2}$ Study status information correct as of May 2021.

that acts as a 'pure' antagonist ${ }^{67}$. Other pure $\alpha v \beta 3$ small-molecule antagonists have been designed, using cryogenic electron microscopy imaging of integrin conformations, that had limited access to the high-affinity conformation of $\alpha v \beta 3$ and did not enhance angiogenesis at low concentrations ${ }^{60}$. Using similar methodology, small-molecule pure antagonists for $\alpha \operatorname{IIb} \beta 3$ were designed that have reduced bleeding in preclinical models ${ }^{68}$. These molecules are traditional RGD ligand mimetics, unlike the RUC series of compounds. Additionally, a high molecular weight polypeptide disintegrin, TMV-7, which recognizes the $\alpha$ IIb $\beta$-propeller domain, does not induce a conformational change in the $\beta 3$-subunit, and maintains the antithrombotic effects with little tendency for bleeding ${ }^{69}$. Several exciting avenues are currently being investigated in the pursuit of safer and more effective integrin inhibitors.

Inhibitors such as TMV-7 that bind allosterically may have fewer unwanted side effects. With this approach in general, the affinity state of the receptor is also probably less relevant, because the binding site is distinct from the orthosteric site. Allosteric molecules could block integrin activation either by occluding the orthosteric site or by inducing a conformational change that shifts the integrin to a low-affinity state. However, and especially for antibodies, reduced selectivity may result if the integrin being targeted contains either an $\alpha$ - or $\beta$-subunit that pairs with multiple other $\beta$ - or $\alpha$-subunits. For example, abituzumab, an antibody that binds to an allosteric site on the av-subunit and blocks the RGD site, likely inhibits all av integrins, and this may broaden the risk of on-target toxic effects and thereby potentially reduce the therapeutic window.
The levels of several integrins are increased on tumours, so targeting these integrins with a conjugated cytotoxic molecule could be an effective strategy to specifically target tumour cells ${ }^{70}$. Instead of directly inhibiting an integrin, this novel approach, using drug conjugates that target $\alpha v \beta 6$, takes advantage of high local expression in diseased tissue compared with relatively low levels elsewhere. Interestingly, the $\beta 7$ subunit, in combination with a number of tumour cell antigens, has also been targeted with a CAR-T cell approach in multiple myeloma ${ }^{46}$ in an effort to improve the immunosuppressive microenvironment of tumours (TABLE 2).

Modifying molecules to reduce their half-lives in the systemic circulation can also ameliorate some potential toxicity. For example, the high-affinity av $\beta 6$-binding small-molecule RGD mimetic, GSK3008348 (5), is internalized and degraded in cells, thereby reducing both lung and systemic drug load following inhaled administration $^{71}$. This molecule is both an agonist of av $\beta 6$ and a functional antagonist of TGF $\beta$, as it indirectly inhibits TGF $\beta$ signalling by reducing TGF $\beta$ activation. Ligand-induced internalization could also be exploited to improve selectivity. For example, if $\alpha v \beta 6$ was the only $a v$-containing integrin to be internalized quickly and return to the cell surface slowly following RGD binding, inhibitors targeting this integrin via an RGD-mimetic interaction would have an additional selectivity bias. The functional consequences of this approach would depend on the type and duration of signalling initiated as a result of internalization, which are not known, but to date there has been no evidence of negative effects.

The general advantages and disadvantages of small versus large integrin inhibitor molecules have been 
Table 3 | Selected integrin inhibitors in clinical trials with reported clinical safety and efficacy data

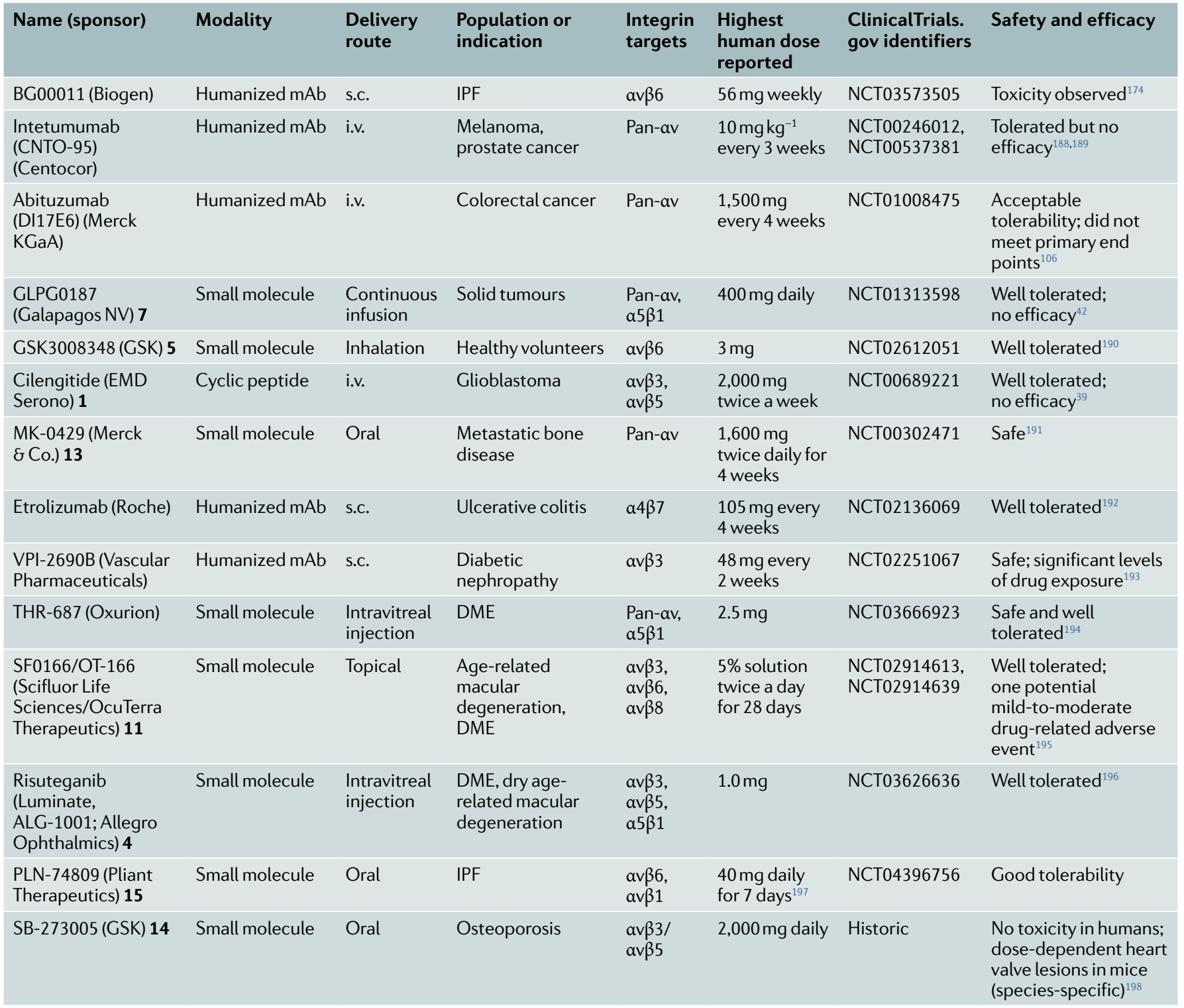

Studies that have published safety, tolerability or efficacy data are included. Numbers in bold refer to the molecule structures in FICS 2,3. DME, diabetic macular oedema; GSK, GlaxoSmithKline; IPF, idiopathic pulmonary fibrosis; i.v., intravenous; mAb, monoclonal antibody; s.c., subcutaneous.

described elsewhere ${ }^{72}$. However, given the seemingly delicate balance between beneficial and detrimental effects derived from full and partial engagement of integrins, from a safety perspective, small molecules may well be better than antibodies because they are cleared from the body in hours, whereas antibody clearance takes days or weeks. It is also easier to have periods of time when no drug is present (for example, if adverse effects arise) and manage receptor occupancy levels with small molecules than with antibodies. Small molecules can also be dosed at home via the oral or inhaled route of administration, whereas antibodies are often dosed at a clinical site by subcutaneous or intraperitoneal injection.

With the breadth and complexity of biology and mechanisms at play within the integrin family, it is likely that only a small component of integrin biology is understood, meaning further research is required to fill the gaps. Do the phenomena observed with certain integrins after drug binding — agonism, internalization and downregulation - also occur with other integrins? More research and an improved set of tool molecules ${ }^{73}$ are required to further dissect these complexities. Indeed, current RGD-binding integrin drug discovery efforts, irrespective of their clinical successes, are likely to catalyse future research because they will deliver a new set of well-characterized tools. These investigations could lead to the successful generation of integrin-targeting drugs.

\section{Diseases involving integrins}

For the subfamily of integrins that contain the av-subunit, a plethora of target validation studies have been completed in fibrotic diseases and oncology. In this section, we summarize the target validation studies that support the hypotheses that integrin inhibition will have a therapeutic benefit in fibrotic diseases, cancer and viral infections. 
<smiles>CNC(=O)[C@H](Cc1ccccc1)NC(=O)[C@H](CC(=O)O)NC(=O)CNC(=O)C(CCCNC(=N)N)NC(=O)C(C(C)C)N(C)C(=O)CC(=O)O</smiles><smiles>CCCCS(=O)(=O)N[C@@H](Cc1ccc(OCCCCC2CCNCC2)cc1)C(=O)O</smiles>

2
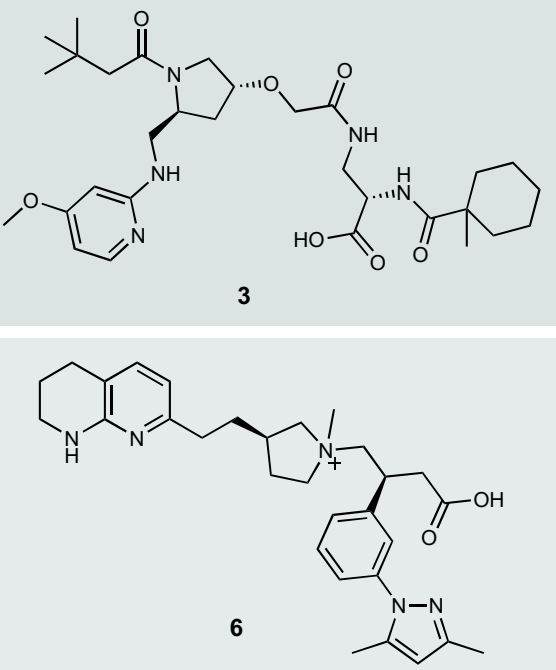

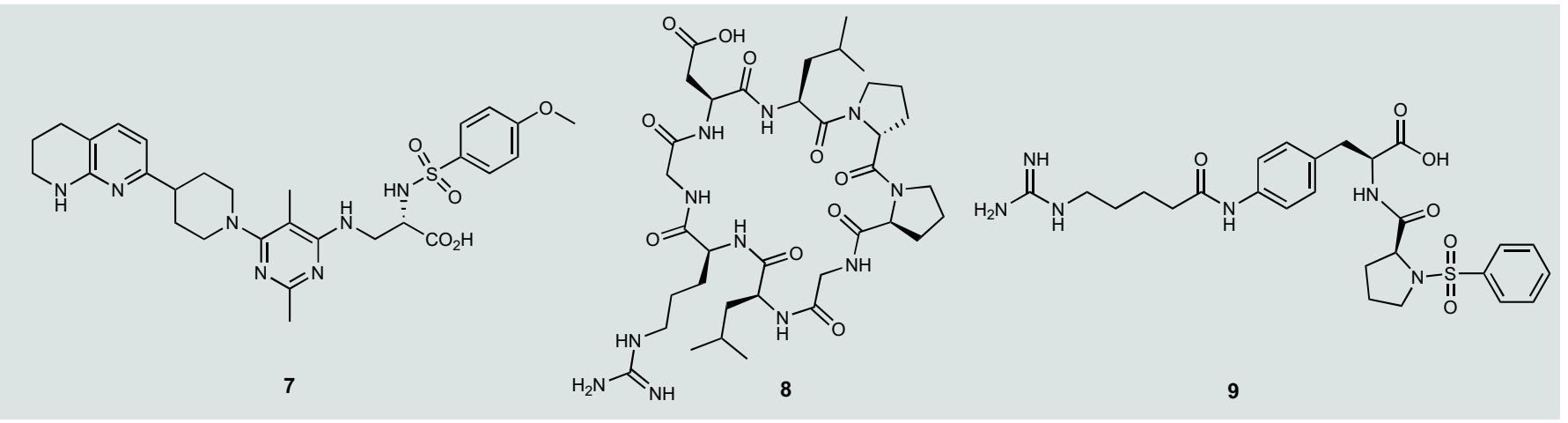<smiles>CC(C)(C)c1cc(Br)cc(C(CC(=O)O)NC(=O)CNC(=O)c2cc(O)cc(NC3=NCC(O)CN3)c2)c1</smiles>

10<smiles>O=C(O)CC(c1ccc(OC(F)F)nc1)N1CCN(CCCc2ccc3c(n2)NCCC3)C1=O</smiles>

11

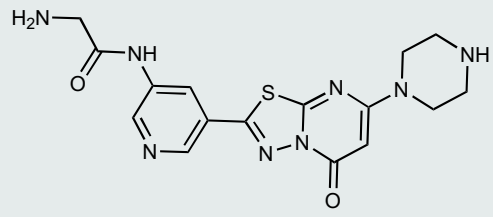

12

Fig. 2 | Selected small molecules with parenteral properties that bind to RGD integrins. The small molecules shown here have either been evaluated in the clinic or have been examined in preclinical models and are administered by a parenteral route with advantageous potency or selectivity profiles. The molecules are: $\mathbf{1}$ cilengitide, $\mathbf{2}$ tirofiban, 3 JSM-6427 (proposed structure); 4 risuteganib (Luminate), 5 GSK3008348, 6 av $\beta 6$ integrin small-molecule inhibitor, 7 GLPG0187, 8 acyclic peptide selective for av $\beta 8,9$ av $\beta 1$ integrin small-molecule inhibitor, 10 CWHM-12, 11 SF0166 (now OT-166), 12 RUC-4. RGD, Arg-Gly-Asp.

Pulmonary fibrosis. Currently, clinical investigations for the antifibrotic potential of integrin inhibitors centre on IPF, a debilitating chronic condition of unknown aetiology. Several $\alpha v$-containing integrins $\left(\alpha v \beta 1\left(\mathrm{REFS}^{74,75}\right)\right.$, $\alpha v \beta 5\left(\mathrm{REF}^{76}\right)$ and $\left.\alpha v \beta 6\left(\mathrm{REF}^{77}\right)\right)$ are upregulated in IPF. $\alpha v \beta 1$ and $\alpha v \beta 6$ are the most thoroughly validated targets; levels of $\alpha v \beta 6$ also have potential prognostic value ${ }^{78}$. Multiple integrins may be involved in IPF: $\alpha v \beta 6$ drives TGF $\beta$ activation in alveolar epithelial cells while av $\beta 1$ mirrors this in myofibroblasts, which characterize and contribute to the development of fibrotic diseases. The contribution of the integrins and cell types to IPF depends on the disease stage; $\alpha v \beta 6$ is implicated in the early phase, during epithelial damage, after which $\alpha v \beta 1$ in myofibroblasts drives the fibrotic foci ${ }^{75}$.

$\alpha v \beta 6$ was the first $\alpha v$ integrin to be identified as crucial in IPF. Gene knockout and pharmacological intervention studies in the bleomycin-induced mouse model of lung fibrosis with a selective $\alpha v \beta 6$ monoclonal antibody, BG00011 (REF. ${ }^{79}$ ) (known as STX-100 and 3G9 preclinically), demonstrated that $\alpha v \beta 6$ deletion or inhibition could prevent the development of fibrosis or reverse established fibrosis, respectively. Later work showed that blocking $\alpha v \beta 1$ with a small-molecule inhibitor (9) in the bleomycin model could reverse established fibrosis $^{75}$, but the lack of selectivity of this molecule, 
which also binds to non- $\alpha v$-containing integrins, suggests that further target validation work is required ${ }^{74}$. It is worth noting that genetic deletion of $\alpha v \beta 1$ is not possible because homozygous $\beta 1$-null mice do not survive through to birth ${ }^{80}$ and therefore a key preclinical tool in the target validation armoury for $\alpha v \beta 1$ is missing. The pan- $\alpha$ v inhibitor MK-0429 (13 in FIG. 3) also reduces fibrosis progression in the bleomycin-induced mouse model ${ }^{81}$, supporting the notion that $\alpha v \beta 1$ and av $\beta 6$ have important roles in fibrosis, but the data from this inhibitor does not differentiate their contributions. However, as the drug was dosed 5 days after bleomycin treatment in this study, during the inflammatory phase of the model rather than in the subsequent fibrotic stage, the results should be treated with caution.

There is some preclinical evidence that $\alpha 3 \beta 1\left(\right.$ REF. $\left.^{82}\right)$, $\alpha 4 \beta 1\left(\mathrm{REF}^{83}\right)$ and $\alpha 8 \beta 1\left(\mathrm{REF}^{84}\right)$ integrins play a role in pulmonary fibrosis, and that $\alpha v \beta 8$ is important in small airway fibrosis associated with chronic obstructive pulmonary fibrosis and asthma ${ }^{85}$. However, these are challenging integrins to target because few selective small molecules and antibody tools exist, and perhaps, as a consequence, to the best of our knowledge, there are no advanced IPF drug discovery campaigns focused on these integrins.

Hepatic fibrosis. Hepatic fibrosis is associated with the end stage of chronic liver diseases such as chronic virusinduced hepatitis $\mathrm{B}$ and hepatitis $\mathrm{C}$, and nonalcoholic fatty liver disease (NAFLD). NAFLD encompasses a range of chronic liver diseases related to obesity, steatosis (accumulation of fat) and NASH that can lead to fibrosis, cirrhosis and hepatocellular carcinoma. In endstage liver disease, av $\beta 6$ protein levels are increased in bile duct epithelia and transitional hepatocytes, and the av $\beta 6$ mRNA levels increase with disease progression in patients with hepatitis $\mathrm{C}^{86}$. In vivo target validation

\section{Box 3 | Activation of TGF $\beta$ via the $\alpha$ integrins}

All five of the Arg-Gly-Asp (RGD)-binding av-containing integrins have been shown to activate the pro-fibrotic mediator transforming growth factor $\beta(\operatorname{TGF} \beta)^{206}$, releasing this growth factor from its inactive state, in which it is bound to latency-associated peptide (LAP) and tethered to the extracellular matrix (ECM). Only the TGF $\beta 1$ and TGF $\beta 3$ isoforms are activated by integrins, as the TGF $\beta 2$-LAP complex lacks the RGD sequence ${ }^{207}$. The activation of latent TGF $\beta$ by the myofibroblast integrins $\alpha v \beta 1$, $\alpha v \beta 3$ and $\alpha v \beta 5$ requires a contractile cytoskeleton, and when fibroblasts differentiate into myofibroblasts, contractility increases, especially after stimulation with growth factors. In similar fashion, $\alpha v \beta 6$ on epithelial cells requires tractive force and cytoskeletal integrity to release TGF $\beta$ from pro-TGF $\beta^{153}$.

Integrins can activate TGF $\beta$ via a protease-dependent or protease-independent pathway. In the case of av $\beta 8$, proteolytic activity is required and matrix metalloproteinase 14 (MMP14) is simultaneously recruited to the LAP RGD site ${ }^{208}$. Proteaseindependent TGF $\beta$ activation by integrins requires these two molecules to be in close proximity, coupled with tractive force, resulting in the presentation of TGF $\beta$ to its cognate receptor $^{209}$. This can perpetuate a feedforward loop whereby TGF $\beta$ upregulates integrin expression and a repertoire of ECM proteins, leading to continual and self-sustaining growth factor activation. The differentiation of myofibroblasts is induced by active TGF $\beta$, and this process is mediated in part through SMAD and the canonical TGF $\beta$ pathway. However, the process may also be stimulated by non-canonical activation of focal adhesion kinase (FAK) through interactions with integrins ${ }^{210}$. Therefore, the pro-fibrotic effects of TGF $\beta$ on fibroblasts are likely caused by integrins on epithelial cells and fibroblasts, which release the active growth factor, as well as autonomous, non-canonical, pro-fibrotic pathways through TGF $\beta$-induced $\alpha v \beta 1$ and FAK. studies for individual integrins have been confined to less-relevant disease models such as the chemically induced carbon tetrachloride $\left(\mathrm{CCl}_{4}\right)$ and the surgerybased bile-duct ligation (BDL) models, which are not particularly representative of end-stage human liver fibrosis. As with IPF, both $\alpha v \beta 1$ and $\alpha v \beta 6$ have been implicated in the development of liver fibrosis, with evidence from genetic deletion or pharmacological inhibition with small molecules or monoclonal antibodies in animal models $s^{75,87,88}$. In addition, pan- $\alpha$ v blockade attenuated fibrosis in a more relevant model of $\mathrm{NASH}^{89}-$ the choline-deficient, amino-acid-defined, high-fat diet model - and further interrogation of this model with selective tools may aid selection of the optimum integrin or integrins to target. The most advanced integrindirected therapy for NASH is the selective $\alpha v \beta 1$ inhibitor PLN-1474, which was recently acquired by Novartis AG from Pliant Therapeutics (TABLE 2).

Chronic kidney disease. In comparison with the target validation data that implicate av-containing integrins in lung and liver fibrosis, the kidney has attracted less attention, possibly because there are no fibrosis-specific surrogate end points for clinical trials, so demonstrating clinical efficacy in short-term studies is difficult ${ }^{90}$. Several chronic renal diseases such as glomerulonephritis, diabetes, IgA nephropathy and Alport syndrome are associated with fibrotic changes and increased av $\beta 6$ expression in epithelial cells ${ }^{91}$. Although some evidence supports a role for $\alpha v \beta 1$ in kidney fibrosis ${ }^{92}$, most target validation studies suggest that $\alpha \mathrm{v} \beta 6$ is more relevant ${ }^{91,93}$. A breakthrough in understanding how to test this hypothesis clinically is needed. Interestingly, Merck recently patented an historic pan-av molecule, MK-0429 (13), for chronic kidney disease ${ }^{94}$. This patent was supported by preclinical evidence; efficacy was demonstrated in a rat in vivo model of diabetic nephropathy ${ }^{95}$.

Skin fibrosis. Skin fibrosis may be present in systemic sclerosis (SSc, a connective tissue disease), hypertrophic scarring and keloid lesions. There is some evidence that integrins have a role in skin fibrosis, specifically SSc, as fibroblasts isolated from disease samples showed elevated levels of activated $\beta 3$-subunits ${ }^{96}$. In addition, the dual $\alpha v \beta 3 / \alpha v \beta 5$ inhibitor cilengitide blocked cutaneous fibrosis when therapeutically administered in a murine model of $\mathrm{SSc}^{97}$. Interestingly, these effects were thought to be due to inhibition of integrin signalling pathways rather than blockade of TGF $\beta$ activation. It is possible that a pan-av integrin inhibitor could be of value in SSc-associated interstitial lung disease (SSc-ILD); in this disease, $\alpha v \beta 6$ is hypothesized to contribute to disease in the lung ${ }^{98}$, and $\alpha v \beta 3$ and/or $\alpha v \beta 5$ may drive the skin manifestations. However, an investigational study using the pan- $\alpha$ v monoclonal antibody abituzumab was terminated for lack of eligible patients (NCT02745145).

Cancer. Numerous integrins, namely $\alpha v \beta 3$, av $\beta 5$ and $\alpha 5 \beta 1$, have been investigated as potential therapeutic targets for various cancers for more than 25 years. The role of integrins in cancer ${ }^{22,99,100}$ has been reviewed 


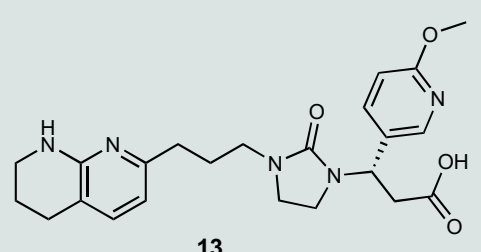

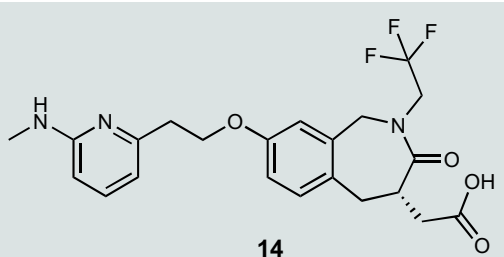

14

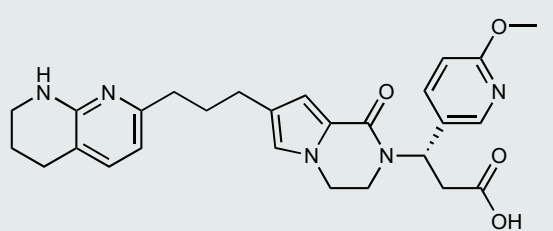

16

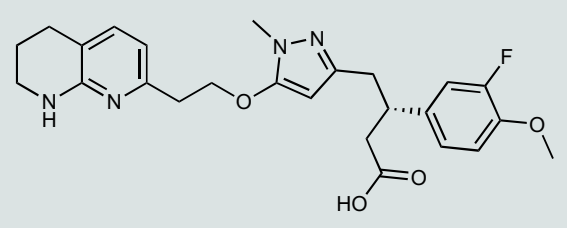

17

$\mathrm{HO}$
15<smiles>COCCN(CCCCc1ccc2c(n1)NCCC2)CC[C@H](Nc1ncnc2ccccc12)C(=O)O</smiles><smiles>C/C=C/CN1CC[C@@](F)(CCc2ccc3c(n2)NCCC3)C1</smiles>

18<smiles>O=C(O)CC(NC(=O)CNC(=O)c1cc(O)cc(NC2=NCC(O)CN2)c1)C(=O)O</smiles>

19

Fig. 3 | Selected small molecules with oral properties that bind to RGD integrins. The small molecules shown here have either been evaluated in the clinic or have been examined in preclinical models and are administered by a parenteral route with advantageous potency or selectivity profiles or are predicted to have these attributes based on their physicochemical properties. The molecules are: 13 MK-0429, 14 SB-273005, 15 PLN-74809 (proposed structure), 16 an example of the series from Bristol-Myers Squibb patent WO2019/094319, 17 an example of the series from St Louis University and Indalo Therapeutics patent WO2018/132268, 18 an example from GlaxoSmithKline's patent WO2016/046226, 19 an example of the series from St Louis University patent WO2017/117538. RGD, Arg-Gly-Asp.

extensively elsewhere but we highlight some of the key findings for inhibitors of av-containing integrins.

Although the rationale for targeting $\alpha v \beta 3$ and $\alpha v \beta 5$ in cancer was plausible based on the preclinical data and the role of these molecules in tumour angiogenesis, this approach has not led to clinical success. Additional cell types may need to be targeted in the tumour microenvironment for these inhibitors to have a benefit ${ }^{38}$. $\alpha v \beta 6$ is also upregulated in several tumours ${ }^{101}$ and could also have prognostic potential ${ }^{102-105}$. Clinical trials have investigated the pan- $\alpha$ v antibodies abituzumab and intetumumab in colorectal carcinoma ${ }^{106}$ and melanoma ${ }^{107}$, respectively, as monotherapies, in combination with chemotherapy or in combination with chemotherapy and an epidermal growth factor receptor inhibitor. Although neither set of studies achieved statistically significant efficacy in its primary end points, there was some evidence of improvement in patients with colorectal carcinoma that expressed high levels of $\alpha v \beta 6$ $\left(\right.$ REF $\left.^{106}\right)$. This suggests that selecting patients who have high av $\beta 6$ expression in the target organ could maximize the chances of clinical efficacy. The selective imaging tools now available ${ }^{108}$ (TABLE 4) could form part of a triage strategy in future trials and for other indications in which $\alpha v \beta 6$ is a potential key driver of disease. With this rationale, selectively targeting av $\beta 6$ with antibodies or peptides may have utility in treating pancreatic cancer ${ }^{109}$ or breast cancer ${ }^{110}$ or as conjugates to antitumour agents ${ }^{111}$.

Specific subsets of cancers are targeted by immunotherapies that disrupt the programmed cell death protein 1 (PD1)-PD1 ligand 1 (PDL1) axis. These surface proteins constitute a receptor-ligand pair and are members of a family of checkpoint inhibitors that moderate immune function and halt the development of a $\mathrm{T}$ cell response $^{112}$. This checkpoint protects the host from autoimmunity and inappropriate immune responses but is inappropriately activated in some tumour microenvironments; overexpression of PDL1 in tumour cells induces tolerance by binding to PD1 on T cells, thereby inhibiting cytotoxic $\mathrm{T}$ cell activation and proliferation, and cytokine secretion. Tumour cells thus evade immune detection ${ }^{113}$. A new class of anticancer immunotherapies that target susceptible PDL1-expressing cancers has emerged over the past decade, and several biologic agents that target this pathway have been approved in cancer ${ }^{114}$.

Recent work highlights three promising independent mechanisms by which integrins may be targeted to treat cancer: reducing the expression of PDL1 in cancer cells, reducing the levels of TGF $\beta$ in the tumour microenvironment and targeting leukocyte integrins to prevent $\mathrm{T}$ cells from homing to tumours. Integrins participate in regulation of PDL1 expression and are thus an important constituent of the immune evasion apparatus. 
av $\beta 3$ positively regulates PDL1 expression in the tumour microenvironment ${ }^{115}$, and in murine studies $\alpha v \beta 3$ depletion restricts the growth of primary tumours ${ }^{116}$. This is particularly relevant because most patients with cancer who receive anti-PD1 or anti-PDL1 therapies do not respond to treatment ${ }^{117}$; anti- $\alpha v \beta 3$ therapy may sensitize tumours to disruption of this axis and therefore be useful in combination with PD1- or PDL1-targeted agents. Because overexpression of $\alpha v \beta 3$ is a common feature in some cancer types and is often associated with poor prognosis, targeting av $\beta 3$ in these cancers could unmask tumours protected by PDL1 overexpression, rendering them susceptible to treatment with an anti-PD1 therapy. Selecting patients on the basis of $\alpha v \beta 3$ expression could increase the likelihood of a positive outcome. Inhibiting integrins other than $\alpha v \beta 3$ may also sensitize tumours to checkpoint inhibitors. For example, inhibition of $\alpha v \beta 6$ induced $T$ cell-mediated immunity in immunotherapy-resistant tumour models ${ }^{118}$.

Similar to $\alpha v \beta 3$, blockade of $\alpha v \beta 8$ has been shown to potentiate a cytotoxic $\mathrm{T}$ cell response in tumours, although these effects seem to be independent of the PD1-PDL1 axis. In contrast to $\alpha v \beta 3, \alpha v \beta 8$ expression in tumours does not usually correlate with PDL1 expression, although $\alpha \mathrm{v} \beta 8$ expression on cancer cells drives tumour growth in vivo. $\alpha v \beta 8$ promotes tumorigenesis through a mechanism different from that of $\alpha v \beta 3$ that may involve TGF $\beta$. In this alternative mechanism of immune evasion, active TGF $\beta$ is released from its latent form, which is present on immune cells, by binding to $\operatorname{av} \beta 8$ on tumour cells ${ }^{119}$ or potentially on immune cells ${ }^{120,121}$. Active TGF $\beta$ in the tumour stroma can prevent the penetration of T cells into the tumour and thus protect tumours from $\mathrm{T}$ cell attack ${ }^{122,123}$.

The success of strategies that directly target $\alpha v \beta 3$ and $\alpha v \beta 8$ will likely be tied to the expression profiles of these integrins on individual tumours, whereas improving $\mathrm{T}$ cell adhesion and activation by targeting leukocyte adhesion integrins should be less dependent on the precise mechanisms by which individual tumours evade host immunity. Allosteric activation of the leukocyte-specific integrins $\alpha \mathrm{L} \beta 2$ and $\alpha 4 \beta 1$ in T cells with the small molecule 7HP349 enhanced T cell activation and adhesion, and thereby improved the penetration of $\mathrm{T}$ cells into tumours in mouse models of melanoma and colon carcinoma ${ }^{124}$. This compound is now in phase I trials (TABLE 2).

Efforts are also being made to conjugate integrinbinding small molecules, peptides and antibodies to bioactive moieties to target specific tissues. Integrins are cell surface receptors and are overexpressed in specific diseased tissues, and are therefore perfect candidates for the application of this technology. So far, efforts have centred on RGD-binding approaches to target delivery of drug conjugates to tumours, and $\alpha v \beta 3$ has been the primary focus owing to its role in the development of tumour vasculature. Proof-of-concept experiments with nanoparticles as the drug moieties and various cyclic RGD peptides as the av $\beta 3$-targeting component demonstrated that these molecules rapidly localized to tissues and induced targeted cytotoxicity in vivo ${ }^{125-127}$. The potential to deliver other tools, such as diagnostic imaging ligands, to tissues is also of interest ${ }^{99,128}$. Studies have successfully delivered therapeutic and imaging compounds to specific tumours and improved the uptake and activity of the bioactive cargo in tumours. Altering the targeting moiety and conjugate design can give this system remarkable flexibility and precision, and this conjugate approach may well lead to successful treatments. Indeed, a recent clinical trial (NCT04389632) has been initiated to investigate an antibody-drug conjugate that recognizes $\beta 6$ to selectively target solid tumours ${ }^{129}$.

Table 4 | Recent clinical imaging studies targeting integrins

\begin{tabular}{|c|c|c|c|c|c|c|}
\hline Tracer (sponsor) & $\begin{array}{l}\text { Imaging } \\
\text { modality }\end{array}$ & $\begin{array}{l}\text { Primary } \\
\text { integrin target }\end{array}$ & Study aim & Indication & $\begin{array}{l}\text { ClinicalTrials. } \\
\text { gov identifier }\end{array}$ & $\begin{array}{l}\text { Study } \\
\text { status }^{\mathrm{a}}\end{array}$ \\
\hline $\begin{array}{l}{ }^{68} \mathrm{Ga}-N O T A-3 P-T A T E-R G D \text { (Peking } \\
\text { Union Medical College Hospital) }\end{array}$ & PET/CT & $\alpha \vee \beta 3$ & Target expression & Lung cancer & NCT02817945 & Unknown \\
\hline$\left[{ }^{18} \mathrm{~F}\right]$ Fluciclatide (GE Healthcare) & PET & $\operatorname{av} \beta 3 / \alpha v \beta 5$ & $\begin{array}{l}\text { Target } \\
\text { expression and } \\
\text { reproducibility }\end{array}$ & Solid tumours & NCT00918281 & Completed \\
\hline$\left[{ }^{18} \mathrm{~F}\right] \mathrm{FBA}-\mathrm{A} 20 \mathrm{FMDV} 2$ (GSK) & PET & $\alpha v \beta 6$ & $\begin{array}{l}\text { Target expression } \\
\text { and engagement }\end{array}$ & IPF & $\begin{array}{l}\text { NCT02052297, } \\
\text { NCT03069989 }\end{array}$ & Terminated \\
\hline $\begin{array}{l}\left.{ }^{18} \mathrm{~F}\right] \mathrm{FBA}-\mathrm{A} 20 \mathrm{FMDV} 2 \text { (Queen Mary } \\
\text { University of London) }\end{array}$ & PET & $\alpha \vee \beta 6$ & Target expression & Cancer & NCT04285996 & $\begin{array}{l}\text { Active, not } \\
\text { recruiting }\end{array}$ \\
\hline $\begin{array}{l}{\left[{ }^{18} \mathrm{~F}\right] a v \beta 6-\mathrm{BP} \text { (University of }} \\
\text { California, Davis) }\end{array}$ & PET/CT & $\alpha \vee \beta 6$ & Target expression & Multiple cancers & NCT03164486 & Recruiting \\
\hline $\begin{array}{l}{\left[{ }^{18} \text { F]FP-R01-MG-F2 (Pliant }\right.} \\
\text { Therapeutics and Stanford } \\
\text { University) }\end{array}$ & PET/CT/MRI & $\alpha \vee \beta 6$ & $\begin{array}{l}\text { Target expression } \\
\text { and engagement }\end{array}$ & $\begin{array}{l}\text { IPF, primary sclerosing } \\
\text { cholangitis, } \\
\text { pancreatic cancer }\end{array}$ & $\begin{array}{l}\text { NCT03183570, } \\
\text { NCT02683824, } \\
\text { NCT04072315 }\end{array}$ & Recruiting \\
\hline 99mTc-3PRGD2 (RDO Pharm) & SPECT/CT & Pan- $\alpha v$ & Target expression & Lung cancer & $\begin{array}{l}\text { NCT03974685, } \\
\text { NCT04233476 }\end{array}$ & $\begin{array}{l}\text { Completed/ } \\
\text { recruiting }\end{array}$ \\
\hline${ }^{99 \mathrm{~m}}$ Tc-RWY (Peking University) & SPECT/CT & a6 & Target expression & Breast cancer & NCT04289532 & Completed \\
\hline
\end{tabular}

The table lists selected tracer compounds that are included in studies registered on www.clinicaltrials.gov. These compounds are under investigation as tools to measure target expression and/or target engagement primarily in cancer and fibrotic indications. CT, computed tomography; GSK, GlaxoSmithKline;

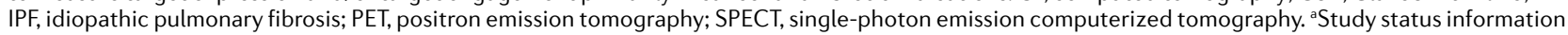
correct as of May 2021. 
Viral infections. In light of the SARS-CoV-2 pandemic of 2020 and beyond it is appropriate to highlight the less explored role that integrins can have in virus transmission. In this regard viruses use various mechanisms, including binding to integrins, to gain cell entry or attachment. By expressing relevant peptide sequences on their surfaces, viruses can bind to integrins to invade host cells, activate intracellular signalling events and mediate disease pathogenesis ${ }^{130}$. Viruses commonly co-opt the RGD recognition sequence, which, in principle, can therefore be targeted to intervene in a range of viral infections ${ }^{131}$. Notably, RGD-binding integrins are used, amongst others, by Zika virus $(\alpha v \beta 5)^{132}$, rotavirus $(\alpha v \beta 3)^{133}$, Ebola virus $(\alpha 5 \beta 1)^{134}$ and foot-andmouth-disease virus ( $\alpha v \beta 6)^{135}$ to gain entry to host cells. However, a potential drawback for the design of integrin inhibitors for this use is the risk of redundancy, whereby alternative cell entry mechanisms are available to viruses to enable rapid evasion from drugs.

Recently, it was postulated that RGD-binding integrins are also co-receptors for angiotensin-converting enzyme 2 (ACE2) ${ }^{136}$, which is used by SARS-CoV-2 for host cell entry; thus, integrin inhibitors could have utility in multiple types of viral infection ${ }^{137}$. In in vitro experiments, the noncompetitive $\alpha 5 \beta 1$ inhibitor, ATN-161, reduced infection ${ }^{138}$. Interestingly, Pliant Therapeutics is investigating its dual $\alpha v \beta 6 / \alpha v \beta 1$ small-molecule inhibitor in a phase II clinical trial (NCT04565249) in patients with COVID-19 and acute respiratory distress syndrome (ARDS).

\section{Drug design for RGD-binding integrins}

Small-molecule inhibitor properties. Small molecules are important for two key reasons: first, as tools and probes ${ }^{139}$ (including imaging molecules; TABLE 4) and secondly as safe and efficacious marketed drugs. Tool molecules, ideally with suitable drug-like characteristics, can answer key mechanistic and biological questions in preclinical settings. For example, integrin inhibitors from UCSF, c8 (9), and from St Louis University, CWHM-12 (10), have been used extensively in target validation studies for fibrotic diseases. However, converting a tool or an early lead into a drug molecule is a challenging and timeconsuming business, and all the knowledge and design is ultimately combined into a single entity, from perhaps many hundreds or even thousands of molecules profiled. Many of the recent integrin clinical candidates are small molecules that have undergone extensive optimization processes and can offer significant benefits, such as in activity and pharmacokinetic profiles, compared with other modalities, including antibodies or larger conjugate molecules. In this section, we therefore discuss the properties of these molecules in detail, the selectivity challenges and how emerging new research could alter future drug design.

It is evident from the low number of molecules that have been developed from research activities and are clinically successful that small-molecule integrin inhibitor drug design is not straightforward. However, for integrins, emerging insights from structural biology and pharmacology research may be game changing. Clearly, the validation of the target in clinically predictive disease models is crucial, but additionally, a key factor to now consider is how molecules affect the integrin conformational states and the relationship - if any - between these states and safety and efficacy. This relationship has not been routinely investigated and research is ongoing, but ideally such efforts would be part of any integrin lead optimization programme, although such endeavours are likely to be resource intensive. The conformational states induced by $\alpha v \beta 3$ and $\alpha \operatorname{IIb} \beta 3$ inhibitors and subsequent signalling is potentially paralleled by other integrins, including other RGD-binding integrins and $\alpha 4 \beta 7$.

There are a substantial number of inhibitors described for integrins, a small subset of which are suitable for clinical evaluation. The vast majority of RGD-binding integrin inhibitors are RGD mimetics with physicochemical properties that are not compatible with oral bioavailability. Much of modern drug design is facilitated and informed by heuristics: Lipinski's 'Rule of Five"140,141 is perhaps the most widely used set of guidelines for drug design. Although these tools are blunt and simplified ${ }^{142}$, they are useful because they are easily applied and allow the rapid design of drug-like molecules. There is also a growing recognition that molecules outside Lipinski drug space, so called 'beyond Rule of Five', are of value for unusual or less tractable targets ${ }^{143,144}$. Compared with marketed oral drugs, most av integrin inhibitors, including those that can be orally dosed, display molecular descriptors that conform less to the Rule of Five and Veber's rules ${ }^{145}$ owing to the intrinsic polar nature of the RGD pharmacophore, with increased molecular weight, an increased number of hydrogen bond donors or acceptors, a higher number of rotatable bonds and larger polar surface area (PSA) (see Supplementary information for a plot of the physicochemical properties of integrin molecules compared with FDA marketed oral drugs). There are also large differences in the properties of integrin inhibitors according to the route of administration those delivered parenterally (FIG. 2) and those delivered orally (FIG. 3). Only molecules from the parenteral class of RGD-binding integrin inhibitors have become marketed drugs (namely tirofiban and eptifibatide), which may reflect the challenges of obtaining high-quality orally bioavailable inhibitors in this physicochemical space (as discussed earlier). Compromises often have to be made to the preferred pharmacological profile to obtain molecules with sufficient permeability and/or bioavailability for clinical use. Approaches to mask the polarity as ester prodrugs have also enabled moderate oral bioavailability for several $\alpha I I b \beta 3$-inhibitor small molecules ${ }^{146,147}$, which demonstrates that ionization, polarity and lipophilicity are important for oral absorption of integrin inhibitors. Although prodrugs are more complex to progress to the market than single drug entities, they can maintain the key potency and selectivity requirements that may otherwise be compromised in favour of oral absorption.

RGD versus non-RGD. Almost all RGD-binding integrin inhibitors are RGD mimetics featuring a mimetic for the guanidine of arginine and a $\beta$-arylpropionic acid or $\alpha$-amino-carboxylic acid to replace the aspartic acid ${ }^{72}$ (FICS 2,3). Such compounds are zwitterionic or 
amphoteric and thus usually charged at physiological $\mathrm{pH}$; this constrains molecular design, and obtaining good oral pharmacokinetics can be challenging. We are unaware of any small-molecule modulators of av integrins that bind outside the orthosteric ligand-binding site, although several large molecules - including an av $\beta 6$ antibody (BG00011, 3G9; Biogen ${ }^{81}$ and ProAgio (an $\alpha v \beta 3$-binding protein) ${ }^{148}$ - have been described. Also, as previously mentioned, ATN-161 is a smallmolecule peptide that binds outside the RGD-binding site of $\alpha 5 \beta 1$. Consequently, new chemotypes that are non-zwitterionic - either basic or acidic but not both would be useful. Such chemotypes would have different physicochemical characteristics from traditional RGD mimetics, and would almost certainly change the nature of the pharmacokinetic design challenge. However, few non-RGD-mimetic compounds have progressed. Many feature functionality that is incompatible with oral bioavailability or are unlikely to demonstrate high passive permeability, and some include structural motifs that are found in pan-assay interference compounds (PAINS) ${ }^{149}$.

RUC-4 (12) is a notable exception. This $\alpha I I b \beta 3$ inhibitor does not have a carboxylic acid (which otherwise forms a strong interaction with the magnesium ion in the binding site), and thus is basic and has non-zwitterionic properties. In the ligand binding site, the primary amine displaces the magnesium ion, locking the receptor in an inactive conformation ${ }^{62,63}$. In addition, GlaxoSmithKline (GSK) designed potent and selective $\alpha v \beta 1$ inhibitors ${ }^{150}$ that, whilst conforming to the general RGD-mimetic motif, were non-zwitterionic, featuring a phenyl urea as a non-basic arginine mimetic. Non-zwitterionic molecules may offer good permeability and absorption while still acting as ligands in the RGD-binding site.

Numerous approaches to identify new small-molecule chemotypes can be considered. Structure-based design could be useful because $\alpha v \beta 3$ and $\alpha v \beta 6$ crystal structures, as well as homology models for other RGD-binding integrins, are available ${ }^{151}$. Crystal structures of integrins in the inactive unbound forms through to the activated ligand-bound forms have been published and these structures have elucidated fundamental principles of integrin activation ${ }^{4,49,50,61,62,67,68,152,153}$. The conformation of the tertiary structure of integrins can change considerably, although the actual binding site regions change less dramatically. Recent publications suggest that ligands for different conformations of $\alpha v \beta 3$ and $\alpha \operatorname{IIb} \beta 3$ can be designed, including peptidic pure antagonists ${ }^{67}$ or small molecules ${ }^{60-62}$. It remains to be seen what effect these compounds have clinically, but pure antagonism of these integrins could overcome previously encountered problems and thus trigger significant renewed interest. In our own experience, however, even if the potency and selectivity of RGD-integrin inhibitors can be rationalized from modelling studies in hindsight, the design of inhibitors de novo from modelling and docking studies is challenging ${ }^{154}$. Similarly, despite NMR studies that identify ligand-binding interactions with av $\beta 6\left(\right.$ REF. $\left.^{155}\right), \alpha \operatorname{IIb} \beta 3\left(\right.$ REF. $\left.^{156}\right)$ and $\alpha v \beta 3\left(\right.$ REF. $\left.^{157}\right)$ in a cellular environment - which more closely reproduces physiological binding - these studies have predominantly provided insights retrospectively.
Combined computational and NMR studies enabled the design of a potent and selective $\alpha v \beta 6$ small peptide from a nonapeptide ${ }^{158}$. In this novel approach, a computationally driven algorithm, using a docking score as proxy for binding activity, successfully predicted active analogues. But by far the most common and successful approach (based on new patent filings) has used existing, published knowledge ${ }^{159}$. As a result, many of these chemotypes look similar to each other, and the structural space is becoming crowded.

Selectivity. The desired integrin selectivity can greatly affect the design of integrin inhibitors. No av-targeting molecules are clinically proven, so pharmacological effects cannot be assigned to specific selectivity profiles. In treating fibrotic diseases, for example, it is unclear which av-containing integrins are pivotal in any particular disease in humans and this is complicated by differing integrin expression levels across the tissues and organs, and in animal models. Validation studies conducted with non-selective tools may therefore shed little light on the precise selectivity requirements to treat a specific disease. However, because non-selective molecules appear to be safe in the clinic (TABLE 3), investing the time and resources to identify the specific selectivity profile in validation studies may not always be necessary. For some applications, though, selectivity is probably important.

Many inhibitors of av-containing integrins share key binding characteristics ${ }^{72}$. The homologous RGD pharmacophore recognition sequence in these integrin binding sites, especially in integrins in which the $\alpha$-subunit binding domains or the $\beta$-subunits are similar, makes the design of highly selective small molecules difficult, even with the help of ligand-protein X-ray crystal structures and the construction of homology models. As a result, a range of selectivity profiles is attainable, but designing molecules that target one specific integrin and not others is challenging.

Inhibitors of av integrins can often be assigned to one of four broad 'selectivity buckets', which indicate likely selectivity profiles: selective dual $\alpha v \beta 3$ and $\alpha v \beta 5$ inhibitors; pan- $\alpha v$ inhibitors; selective dual $\alpha v \beta 6$ and $\alpha v \beta 8$ inhibitors; and selective $\alpha v \beta 1$ inhibitors (selective for $\alpha v \beta 1$ over the other $\alpha v$-containing integrins). Molecules in this final group may inhibit other $\beta 1$-containing integrins, and it is too early to assign additional av selectivity patterns to these inhibitors, but will also constitute a bucket. Although most compounds fall into one of these buckets, the selectivity profile of a compound may have been either intentional or merely tolerated. Obtaining selectivity for $\alpha v \beta 3$ and $\alpha v \beta 5$ over $\alpha v \beta 6$ and $\alpha v \beta 8$ or vice versa is relatively straightforward, but obtaining selectivity within these buckets or pairs is challenging, owing to the subtle differences in binding site architecture, and is less well understood. However, for examples where selectivity has indeed been achieved within a bucket, changes are often made to the parts of the molecule that bind to the 'specificity-determining loop ${ }^{\text {'72 }}$.

Few small molecules with selectivity for $\alpha v \beta 5$ (particularly over $\alpha v \beta 3$ ) or $\alpha v \beta 8$ (particularly over $\alpha v \beta 6$ ) exist, although an acyclic peptide $(8)^{160}$ that is selective for $\alpha v \beta 8$, and $\alpha v \beta 5$-selective molecules ${ }^{161}$, have been 
identified. Interestingly, the current clinical molecule, SF0166 (11), is reported to be selective for $\alpha v \beta 3$ over $\alpha v \beta 5$ by virtue of only small structural changes ${ }^{34}$. Additionally, a few $\alpha v \beta 6$ inhibitors have good selectivity over $\alpha v \beta 8$, such as compounds from GSK $(\mathbf{5}, \mathbf{6})^{154,162}$. Antibodies that bind to the various RGD integrins have already been described and have a range of selectivity profiles ${ }^{72}$.

Interestingly, some of the small-molecule $\alpha \mathrm{v} \beta 3$ inhibitor lead molecules came from $\alpha \mathrm{IIb} \beta 3$ compounds and some of the $\alpha v \beta 6$ leads originated from in-house $\alpha v \beta 3$ leads ${ }^{163}$, so molecules with different selectivity profiles from the desired profile can be useful starting points.

Given the current clinical potential of av $\beta 6$ inhibitors, can selective $\alpha v \beta 6$ small-molecule inhibitors be developed using the wealth of information already available for published $\alpha v \beta 3$ molecules? Some specific design tricks could be used to switch selectivity. Many av $\beta 6$ inhibitors (for example, molecules 5, 15 and 18) have basic linker regions, whereas $\alpha v \beta 3 / \alpha v \beta 5$ inhibitors (for example, 13 and 14) often have neutral, non-ionizable linkers. The basic group interacts with a threonine residue that is present in $\operatorname{av} \beta 6$ but absent in $\alpha v \beta 3$ and $\alpha v \beta 5$. The molecule (6), which is analogous to the inhaled candidate (5), contains a methyl quaternized nitrogen ${ }^{162}$ in the linker region, and the presence of this ionized nitrogen increases the potency and selectivity for $a v \beta 6$. Unfortunately, these advantages come at the expense of low permeability and reduced oral bioavailability, so this molecule (6) and similar molecules are more suitable for parenteral administration. As with all small-molecule drug design, the properties of molecules are intertwined, and structural changes to optimize selectivity may make optimization of other parameters, such as oral bioavailability, more challenging.

Similarly, certain structural motifs have affinity for specific subunits. The bulky sulfonamide contained in (9), or similar analogues, binds strongly to the $\beta 1$-subunit and consequently this molecule interacts with several other $\beta 1$-containing integrins, such as $\alpha 4 \beta 1$ (REF. $\left.{ }^{164}\right), \alpha 2 \beta 1$ (REF. ${ }^{165}$ ), and $\alpha v \beta 1$ (REF. ${ }^{166}$ ).

In the absence of an $\alpha v \beta 1$-selective antibody, small-molecule tools (such as $\mathbf{9}$ ) have proved invaluable for initial target validation studies in fibrotic diseases. However, because it also binds to other $\beta 1$-containing integrins, this molecule may be less useful to pinpoint the importance of specific integrins as relevant targets ${ }^{74}$. This integrin cross-reactivity highlights the need for comprehensive cross-screening. However, such screening is less available: unlike kinase screening panels, which are commercially available (example firms are MRC PPU and Eurofins; see Related links); integrin screening panels are not. Furthermore, the observed potency and selectivity of ligands also depend on the type of assay, conditions and set-up, which can make inter-compound comparisons less robust. We recently tested a comprehensive set of tools that bind av-containing integrins in the same assays $^{72}$, and the profiles of peptidic tools have also been compared $^{167}$.

Several molecules have activity at multiple av integrins, including $a v \beta 6$, and are orally bioavailable. Such molecules have been developed by Pliant (15) ${ }^{168}$, GSK $(\mathbf{1 8})^{169}$ and St Louis University (19) ${ }^{170}$, and show good permeability. In each of these examples, the linker is either neutral, or the $\mathrm{p} K_{\mathrm{a}}$ of the basic nitrogen in the linker is modulated by virtue of a proximal fluorine or ether functional group. Molecular conformational flexibility can also allow intramolecular folding to 'hide' ionized functionality ${ }^{171,172}$, but this can complicate the molecular design even further.

\section{Clinical data}

The key integrin inhibitors in ongoing clinical studies are summarized in TABLE 2 and those that have completed clinical trials are listed in TABLE 3 with highest clinical dose, safety and efficacy information. The majority of studies target or have targeted the av-containing integrins, particularly av $\beta 6$ and $\alpha v \beta 3$. The most advanced clinical molecule currently in clinical trials is the oral dual $\alpha v \beta 1 / \alpha v \beta 6$ inhibitor, PLN-74809 (15; Pliant Therapeutics), which is currently in phase II for IPF (NCT04072315). Targeting the lung specifically has also been investigated with the inhaled and selective $\alpha v \beta 6$ small molecule GSK3008348 (5; GSK) $)^{71}$ but this programme has been strategically placed on hold, despite observed target engagement in a phase Ib study of IPF using an imaging readout ${ }^{173}$ (TABLE 4). The development of the $\alpha v \beta 6$-selective antibody from Biogen (BG00011) was recently terminated because of undisclosed safety concerns ${ }^{174}$, and the development of the pan- $\alpha v$ integrin inhibitor IDL-2965 (NCT03949530) for NASH was also terminated. It remains to be seen whether these setbacks will deter companies such as GSK, Pliant Therapeutics, Bristol-Myers Squibb and Morphic Therapeutics, which hold patents describing molecules with varying av activities (molecules 15-18) ${ }^{159}$.

Both pan- $\alpha v$ antibodies and small molecules appear to be well tolerated in humans (TABLE 3), although the lack of efficacy for several molecules suggests that target engagement may have been insufficient to test for potential mechanism-based toxicity. Although the clinical data from BG00011, which was terminated for undisclosed safety reasons, raises potential safety concerns about selective av $\beta 6$ inhibition, small doses of the inhaled selective inhibitor $\mathbf{5}$ were well tolerated. It is possible that sustained $\alpha v \beta 6$ inhibition detrimentally affects the anti-inflammatory and protective roles of this integrin, and in an already compromised fibrotic lung, this could become a risk. The corollary, therefore, is that there is only a small therapeutic window for targeting av $\beta 6$ in the lung, so the dose and therapeutic modality are particularly important. A study in chronic allograft dysfunction was also withdrawn for BG00011 (then named STX-100, NCT00878761) before recruitment of patients, potentially as a result of preclinical work indicating a protective role for $\alpha v \beta 6$ (REF. ${ }^{175}$ ).

Although the marketed drug abciximab therapeutically targets $\alpha \mathrm{IIb} \beta 3$, it also appreciably inhibits $\alpha v \beta 3$ (REF. ${ }^{176}$ ), adding further evidence that targeting $\alpha v \beta 3$ is safe in humans. Cilengitide, too, has been widely explored clinically and seems to have failed for efficacy rather than safety reasons. Although the dosing route is not correlated with toxicity, inhaled dosing may be advantageous for treating diseases of the lung, as it could result in lower systemic drug levels. 
As for other therapeutic areas, the generation of translational biomarkers, the demonstration of target engagement and the development of pharmacokinetic and pharmacodynamic relationships are key to understanding the chances of success. In the integrin field, there are few historical studies in which these characteristics have been evaluated, but studies have recently begun to take this translational approach. For example, the target engagement of GSK3008348 (5) was demonstrated using an $\alpha v \beta 6$-specific radiolabelled peptide ligand in bleomycin-treated mice via single-photon emission computerized tomography (SPECT) $)^{71}$ and confirmed in patients with IPF via positron emission tomography (PET) ${ }^{173}$. In addition, the functional consequences of $\alpha v \beta 6$ integrin inhibition (using levels of phosphorylated SMAD, a marker for TGF $\beta$ activation) have been measured in bronchoalveolar lavage fluid from healthy subjects or patients with IPF, and used as a pharmacodynamic measurement to optimize the dose ${ }^{177}$.

Reagents to image av-containing integrins (TABLE 4) have been used to define integrin expression levels and to determine whether a drug engages its target. As integrins themselves could have prognostic value - for example, levels of av $\beta 6$ in IPF and cancer - imaging an integrin in patients could be used to track disease progression. This approach could also be used to select for patients with either high levels of target expression or rapidly progressing forms of disease. For example, a retrospective analysis of $\alpha v \beta 6$ expression in patients with colorectal carcinoma who received the pan- $\alpha$ v antibody abituzumab suggested that individuals with high expression levels were more likely to benefit from the therapy ${ }^{106}$.

\section{Challenges and prospects}

Considering how many drug discovery projects and clinical studies have focused on integrins over the past 30 years, the number of approved therapies has been disappointing ${ }^{5,26}$. Translating the potential, and indeed the validity, of the preclinical integrin data into clinically efficacious drugs is clearly not without complexity. These clinical failures likely reflect a combination of challenges that are generic to drug development and those that are target-class specific. Many of the integrin inhibitors that were tested historically had suboptimal pharmacokinetics, with routes of administration and dosing regimens that led to poor exposure and target coverage, which is a generic challenge for small-molecule drug development ${ }^{14,72}$. This, coupled with a lack of clinical pharmacodynamic biomarkers to measure target engagement, left the relevance of integrins in the disease of interest unknown, as molecules often failed to test the hypothesized mechanism. Conversely, target coverage as a result of poor pharmacokinetics was less of an issue for the large molecules (such as antibodies) that were tested in the clinic, and indeed these have arguably shown more potential. A retrospective analysis of the abituzumab clinical trial data, for example, suggested that the drug had some clinical benefit in patients with higher expression of av $\beta 6$ (REF. $\left.{ }^{106}\right)$. Therefore, identifying patients with higher target expression levels might improve success, and although this seems be a logical approach for any target class, it has rarely been employed for integrins. This is probably because, in practice, it is difficult to measure expression levels in the clinic without negatively affecting patient recruitment and the time needed to complete studies, and because the ultimate market for the drug will be smaller if the label granted is narrowed to only those patients who express high levels of integrins.

As with any drug discovery area, some potentially interesting compounds have not progressed because of strategic decisions. Even if a compound has demonstrated some potential and there is a clear next step, the programme may no longer be attractive. Projects can also be placed on hold or terminated if a company refocuses their goals, as when AstraZeneca shelved their dual $\alpha v \beta 6 / \alpha v \beta 8$ monoclonal antibody (RAD264) $)^{178}$, or loses confidence in a target because of negative clinical results or safety concerns from competitor trials.

A further generic challenge is the translation of preclinical in vivo pharmacodynamic studies to the clinic. These studies are still of value for investigating pharmacokinetic and pharmacodynamic relationships in a whole-body system, but their capacity to accurately represent human biology, especially human diseases, is often questionable and the data generated can therefore become supportive instead of essential ${ }^{179}$. Even safety studies in animal models of the disease are not ideal because the models themselves are not necessarily translatable to the human disease and the animals can be highly compromised. These limitations to preclinical pharmacodynamic and safety studies can result in on-target safety issues in the clinic, such as those observed with the $\alpha 4$ inhibitors and the av $\beta 6$ monoclonal antibody BG00011, which can be difficult to predict or discover early in the process. Studies in diseased human tissue, especially in fibrosis, may therefore further aid validation and translation as more relevant disease systems and surrogates are developed ${ }^{71,180,181}$.

There are also class-specific challenges to therapeutically targeting integrins. The lack of selective drug-like tools for this target class, especially because the same subunit is part of multiple different integrins and there are many subunits within integrin subfamilies, has made interpretation and therefore translation of preclinical data difficult. Similarly, measuring expression levels of integrins within these subfamilies is difficult if heterodimer-specific antibodies do not exist. This makes correlating expression levels of the key integrins in the organ of interest in in vivo models with levels in diseased human tissue a challenge, which likely contributes to the failures in this field. Developing small molecules with high affinity and selectivity for an integrin, while maintaining the required physicochemical properties and optimal pharmacokinetic profile for oral dosing, has also been difficult. Even circumventing this with large molecules, such as biologics, is not always successful.

New target validation tools for drug discovery using technologies based on genomics, transcriptomics, proteomics and metabolomics will allow more detailed and global analyses of disease cohorts. For example, genome-wide association studies (GWAS) can identify genetic variations that occur more frequently in people 
with a disease than in those without. Targets with genetic associations are estimated to be twice as likely to succeed in clinical development ${ }^{182}$. Although there are few associations between diseases and changes in integrin-related genes, there is an indirect association between $\alpha v \beta 6$ and IPF. A variation of $A K A P 13$ was identified as a potential genetic risk factor in $\mathrm{IPF}^{183}$, and AKAP13 mediates activation of TGF $\beta$ downstream of $\alpha \mathrm{v} \beta 6\left(\mathrm{REF}^{184}\right)$. Although these tools have yet to be fully applied to integrin target validation, they will undoubtedly be an important part of this process in the future.

Although integrins fell out of favour as targets for drug development, there has been renewed interest and investment in the integrins as drug targets, particularly for fibrotic diseases. To be successful, current integrin programmes should note the key lessons from the many integrin-targeted trials that have already been completed. Future integrin-targeted programmes should focus on the development of molecules that enable hypothesized mechanisms to be fully tested; robust target validation; clinical studies that measure target engagement; and translational biomarkers to measure clinical efficacy. With these changes, indications including fibrosis and cancer, which were previously targeted with little success, may be re-evaluated with improved therapeutic agents.

\section{Published online 17 September 2021}

1. Hynes, R. O. Integrins: a family of cell surface receptors. Cell 48, 549-554 (1987).

2. Hynes, R. O. Integrins: bidirectional, allosteric signaling machines. Cell 110, 673-687 (2002).

3. Faull, R. J. \& Ginsberg, M. H. Inside-out signaling through integrins. J. Am. Soc. Nephrol. 7, 1091-1097 (1996).

4. Zhu, J. et al. Requirement of alpha and beta subunit transmembrane helix separation for integrin outsidein signaling. Blood 110, 2475-2483 (2007).

5. Shattil, S. J., Kim, C. \& Ginsberg, M. H. The final steps of integrin activation: the end game. Nat. Rev. Mol. Cell. Biol. 11, 288-300 (2010).

6. Klapholz, B. \& Brown, N. H. Talin - the master of integrin adhesions. J. Cell Sci. 130, 2435-2446 (2017).

7. Calderwood, D. A., Campbell, I. D. \& Critchley, D. R. Talins and kindlins: partners in integrin-mediated adhesion. Nat. Rev. Mol. Cell Biol. 14, 503-517 (2013).

8. Humphries, J. D., Byron, A. \& Humphries, M. J. Integrin ligands at a glance. J. Cell Sci. 119, 3901-3903 (2006)

9. Ruoslahti, E. RGD and other recognition sequences for integrins. Annu. Rev. Cell Dev. Biol. 12, 697-715 (1996).

10. Gullberg, D. E. \& Lundgren-Akerlund, E. Collagenbinding I domain integrins - what do they do? Prog. Histochem. Cytochem. 37, 3-54 (2002).

11. Aumailley, M. The laminin family. Cell Adh. Migr. 7, 48-55 (2013).

12. Zeltz, C. \& Gullberg, D. The integrin-collagen connection - a glue for tissue repair? J. Cell Sci. 129 653-664 (2016)

13. Stipp, C. S. Laminin-binding integrins and their tetraspanin partners as potential antimetastatic targets. Expert Rev. Mol. Med. 12, e3 (2010)

14. Cox, D. How not to discover a drug - integrins. Expert Opin. Drug Discov . 16, 197-211 (2020)

15. Fullard, J. F. The role of the platelet glycoprotein IIb/Illa in thrombosis and haemostasis. Curr. Pharm. Des. 10, 1567-1576 (2004).

16. Perez, V. L., Pflugfelder, S. C., Zhang, S., Shojaei, A. \& Haque, R. Lifitegrast, a novel integrin antagonist for treatment of dry eye disease. Ocul. Surf. 14, 207-215 (2016).

17. Mitroulis, I. et al. Leukocyte integrins: role in leukocyte recruitment and as therapeutic targets in inflammatory disease. Pharmacol. Ther. 147, 123-135 (2015)

18. Gordon, F. H. et al. A randomized placebo-controlled trial of a humanized monoclonal antibody to alpha4 integrin in active Crohn's disease. Gastroenterology 121, 268-274 (2001).

19. Léger, O. J. et al. Humanization of a mouse antibody against human alpha-4 integrin: a potential therapeutic for the treatment of multiple sclerosis. Hum. Antibodies 8, 3-16 (1997).

20. Biogen reports record revenues for both the full year and fourth quarter of 2017, \$12.3 billion and $\$ 3.3$ billion, respectively. Businesswire https://www. businesswire.com/news/home/20180125005353/ en/Biogen-Reports-Record-Revenues-Full-Year-Fourth (2018).

21. Tong, A. Takeda reports second Phlll win for subcutaneous Entyvio as regulators review expanded use. Endpoints https://endpts.com/takeda-reportssecond-phiii-win-for-subcutaneous-entyvio-asregulators-review-expanded-use/ (2019).
22. Raab-Westphal, S., Marshall, J. F. \& Goodman, S. L. Integrins as therapeutic targets: successes and cancers. Cancers 9, 110 (2017).

23. Xie, B. et al. Idiopathic pulmonary fibrosis registry china study (PORTRAY): protocol for a prospective, multicentre registry study. BMJ Open 10, e036809 (2020).

24. Abeysekera, K. et al. Prevalence of steatosis and fibrosis in young adults in the UK: a population-based study. Lancet Gastroenterol. Hepatol. 5, 295-305 (2020).

25. Kumar, C. C. Signaling by integrin receptors. Oncogene 17, 1365-1373 (1998)

26. Goodman, S. L. \& Picard, M. Integrins as therapeutic targets. Trends Pharmacol. Sci. 33, 405-412 (2012).

27. Desgrosellier, J. S. $\&$ Cheresh, D. A. Integrins in cancer: biological implications and therapeutic opportunities. Nat. Rev. Cancer 10, 9-22 (2010).

28. Friedlander, $M$. et al. Involvement of integrins alpha $v$ beta 3 and alpha $v$ beta 5 in ocular neovascular diseases. Proc. Natl Acad. Sci. USA 93, 9764-9769 (1996).

29. Wilder, R. L. Integrin alpha $V$ beta 3 as a target for treatment of rheumatoid arthritis and related rheumatic diseases. Ann. Rheum. Dis. 61, ii96-ii99 (2002).

30. Nakamura, I., Duong, L. T., Rodan, S. B. \& Rodan, G. A Involvement of alpha(v)beta3 integrins in osteoclast function. J. Bone Miner. Metab. 25, 337-344 (2007).

31. Jin, H. \& Varner, J. Integrins: roles in cancer development and as treatment targets. Br. J. Cancer 90, 561-565 (2004)

32. Van Hove, I. et al. Targeting RGD-binding integrins as an integrative therapy for diabetic retinopathy and neovascular age-related macular degeneration. Prog. Retin. Eye Res. https://doi.org/10.1016/ j.preteyeres.2021.100966 (2021).

33. Bhatwadekar, A. D., Kansara, V., Luo, Q. \& Ciulla, T. Anti-integrin therapy for retinovascular diseases. Expert Opin. Investig. Drugs 29, 935-945 (2020).

34. Askew, B. C., Furuya, T. \& Edwards, D. S. Ocular distribution and pharmacodynamics of SF0166, a topically administered $\alpha v \beta 3$ integrin antagonist, for the treatment of retinal diseases. J. Pharmacol. Exp. Ther. 366, 244-250 (2018)

35. Zahn, G. et al. Preclinical evaluation of the novel small-molecule integrin alpha5beta 1 inhibitor JSM6427 in monkey and rabbit models of choroidal neovascularization. Arch. Ophthalmol. 127. 1329-1335 (2009).

36. Silva, R. et al. Tyrosine kinase blocking collagen IV-derived peptide suppresses ocular neovascularization and vascular leakage. Sci. Transl. Med. 9, eaai8030 (2017).

37. Mirando, A. C. et al. A collagen IV-derived peptide disrupts $\alpha 5 \beta 1$ integrin and potentiates Ang $2 / \mathrm{Tie} 2$ signaling. JCI Insight 4, e 122043 (2019).

38. Alday-Parejo, B., Stupp, R. \& Rüegg, C. Are integrins still practicable targets for anti-cancer therapy? Cancers 11, 978 (2019)

39. Stupp, R. et al. Cilengitide combined with standard treatment for patients with newly diagnosed glioblastoma with methylated MGMT promoter (CENTRIC EORTC 26071-22072 study): a multicentre, randomised, open-label, phase 3 trial. Lancet Oncol. 15, 1100-1108 (2014)

40. Mason, W. P. End of the road: confounding results of the CORE trial terminate the arduous journey of cilengitide for glioblastoma. Neuro. Oncol. 17, 634-635 (2015)

41. Hersey, P. et al. A randomized phase 2 study of etaracizumab a monoclonal antibody against integrin alpha(v)beta(3), + or - dacarbazine in patients with stage IV metastatic melanoma. Cancer 116 1526-1534 (2010).

42. Cirkel, G. A. et al. A dose escalating phase I study of GLPG0187, a broad spectrum integrin receptor antagonist, in adult patients with progressive high-grade glioma and other advanced solid malignancies. Invest. New Drugs 34, 184-192 (2016).

43. Shergalis, A., Bankhead, A. III, Luesakul, U., Muangsin, N. \& Neamati, N. Current challenges and opportunities in treating glioblastoma. Pharmacol. Rev. 70, 412-445 (2018)

44. Costa, A. G., Cusano, N. E., Silva, B. C., Cremers, S \& Bilezikian, J. P. Cathepsin K: its skeletal actions and role as a therapeutic target in osteoporosis. Nat. Rev. Rheumatol. 7, 447-456 (2011).

45. Ammar, M. J., Hsu, J., Chiang, A., Ho, A. C. \& Regillo, C. D. Age-related macular degeneration therapy: a review. Curr. Opin. Ophthalmol. 31, 215-221 (2020)

46. Hosen, N. et al. The activated conformation of integrin $\beta 7$ is a novel multiple myeloma-specific target for CAR T cell therapy. Nat. Med. 23, 1436-1443 (2017).

47. Wallstabe, L. et al. CAR T cells targeting av $\beta 3$ integrin are effective against advanced cancer in preclinical models. Adv. Cell Gene Ther. 1, e 11 (2018).

48. Whilding, L. M. et al. Targeting of aberrant $\alpha \vee \beta 6$ integrin expression in solid tumors using chimeric antigen receptor-engineered T cells. Mol. Ther. 25, 259-273 (2017).

49. Yu, Y., Schürpf, T. \& Springer, T. A. How natalizumab binds and antagonizes a 4 integrins. J. Biol. Chem. 288, 32314-32325 (2013).

50. Luo, B. H., Carman, C. V. \& Springer, T. A. Structural basis of integrin regulation and signaling. Annu. Rev. Immunol. 25, 619-647 (2007).

51. Ramsay, A. G. et al. HS1-associated protein X-1 regulates carcinoma cell migration and invasion via clathrin-mediated endocytosis of integrin alphavbeta6. Cancer Res. 67, 5275-5284 (2007).

52. Bassler, N. et al. A mechanistic model for paradoxical platelet activation by ligand-mimetic alphallb beta3 (GPIlb/Illa) antagonists. Arterioscler. Thromb. Vasc. Biol. 27, e9-e15 (2007).

53. Aster, R. H., Curtis, B. R., McFarland, J. G. $\&$ Bougie, D. W. Drug-induced immune thrombocytopenia: pathogenesis, diagnosis, and management. J. Thromb. Haemost. 7, 911-918 (2009).

54. Ley, K., Rivera-Nieves, J., Sandborn, W. J. \& Shattil, S Integrin-based therapeutics: biological basis, clinical use and new drugs. Nat. Rev. Drug Discov. 15 173-183 (2016)

55. Cannon, C. P. et al. Oral glycoprotein Ilb/Illa inhibition with orbofiban in patients with unstable coronary syndromes (OPUS-TIMI 16) trial. Circulation 102 149-156 (2000).

56. Reynolds, A. R. et al. Stimulation of tumor growth and angiogenesis by low concentrations of RGD-mimetic integrin inhibitors. Nat. Med. 15, 392-400 (2009).

57. Weis, S. M., Stupack, D. G. \& Cheresh, D. A. Agonizing integrin antagonists? Cancer Cell 15, 359-361 (2009). 
58. Ehlert, F. J., Suga, H. \& Griffin, M. T. Analysis of agonism and inverse agonism in functional assays with constitutive activity: estimation of orthosteric ligand affinity constants for active and inactive receptor states. J. Pharmacol. Exp. Ther. 338, 671-686 (2011).

59. Wong, P. P. et al. Dual-action combination therapy enhances angiogenesis while reducing tumor growth and spread. Cancer Cell 27, 123-137 (2015).

60. Li, J. et al. Novel pure $\alpha \mathrm{V} \beta 3$ integrin antagonists that do not induce receptor extension, prime the receptor, or enhance angiogenesis at low concentrations. ACS Pharmacol. Transl. Sci. 2, 387-401 (2019).

61. Zhu, J. et al. Closed headpiece of integrin allb $\beta 3$ and its complex with an allb $\beta 3$-specific antagonist that does not induce opening. Blood 116, 5050-5059 (2010).

62. Zhu, J. et al. Structure-guided design of a high-affinity platelet integrin allb $\beta 3$ receptor antagonist that disrupts $\mathrm{Mg}^{2+}$ binding to the MIDAS. Sci. Transl. Med. 4, 125ra32 (2012).

63. Li, J. et al. RUC-4: a novel allb $\beta 3$ antagonist for prehospital therapy of myocardial infarction. Arterioscler. Thromb. Vasc. Biol. 34, 2321-2329 (2014).

64. CeleCor initiates CELEBRATE, a pivotal clinical trial of subcutaneously administered Zalunfiban (RUC-4) in STEMI patients treated in ambulances. https://www. celecor.com/blog/https/wwwcelecorcom (2021).

65. Kereiakes, D. J. et al. First human use of RUC-4: a nonactivating second-generation small-molecule platelet glycoprotein IIb/IIla (integrin allb $\beta 3$ ) inhibitor designed for subcutaneous point-of-care treatment of ST-segment-elevation myocardial infarction. J. Am Heart Assoc. 9, e016552 (2020)

66. Morphic Therapeutic. MINT platform and strategy. https://morphictx.com/our-technology/mint-platformand-strategy (2018)

67. Van Agthoven, J. F. et al. Structural basis for pure antagonism of integrin $\alpha \mathrm{V} \beta 3$ by a high-affinity form of fibronectin. Nat. Struct. Mol. Biol. 21, 383-388 (2014).

68. Adair, B. D. et al. Structure-guided design of pure orthosteric inhibitors of allb $\beta 3$ that prevent thrombosis but preserve hemostasis. Nat. Commun. $11,398(2020)$

69. Kuo, Y. J., Chen, Y. R., Hsu, C. C., Peng, H. C. \& Huang, T. F. An allb $\beta 3$ antagonist prevents thrombosis without causing Fc receptor $\gamma$-chain Ila-mediated thrombocytopenia. J. Thromb. Haemost. 15, 2230-2244 (2017)

70. Marelli, U. K., Rechenmacher, F., Sobahi, T. R., Mas-Moruno, C. \& Kessler, H. Tumor targeting via integrin ligands. Front. Oncol. 3, 222 (2013).

71. John, A. E. et al. Translational pharmacology of an inhaled small molecule $\alpha v \beta 6$ integrin inhibitor for idiopathic pulmonary fibrosis. Nat. Commun. 11, 4659 (2020).

72. Hatley, R. et al. An av-RGD integrin inhibitor toolbox: drug discovery insight, challenges and opportunities. Angew. Chem. Int. Ed. Engl. 57, 3298-3321 (2018).

73. Arrowsmith, C. H. et al. The promise and peril of chemical probes. Nat. Chem. Biol. 11, 536-541 (2015).

74. Wilkinson, A. L., Barrett, J. W. \& Slack, R. J. Pharmacological characterisation of a tool $a v \beta 1$ integrin small molecule RGD-mimetic inhibitor. Eur. J. Pharmacol. 842, 239-247 (2019).

75. Reed, N. I. et al. The $a v \beta 1$ integrin plays a critical in vivo role in tissue fibrosis. Sci. Transl. Med. 7, 288ra79 (2015).

76. Scotton, C. J. \& Chambers, R. C. Bleomycin revisited: towards a more representative model of IPF? Am. J. Physiol. Lung Cell Mol. Physiol. 299, L439-L441 (2010)

77. Horan, G. S. et al. Partial inhibition of integrin alpha(v)beta6 prevents pulmonary fibrosis without exacerbating inflammation. Am. J. Respir. Crit. Care Med. 177, 56-65 (2008)

78. Saini, G. et al. $\alpha v \beta 6$ integrin may be a potential prognostic biomarker in interstitial lung disease Eur. Respir. J. 46, 486-494 (2015).

79. Weinreb, P. H. et al. Function-blocking integrin alphavbeta 6 monoclonal antibodies: distinct ligandmimetic and nonligand-mimetic classes. J. Biol. Chem. 279, 17875-17887 (2004)

80. Stephens, L. E. et al. Deletion of beta 1 integrins in mice results in inner cell mass failure and periimplantation lethality. Genes Dev. 9, 1883-1895 (1995).

81. Zhang, J. et al. Discovery of a new class of integrin antibodies for fibrosis. Sci. Rep. 11, 2118 (2021).
82. Kim, K. K. et al. Epithelial cell alpha3beta 1 integrin links beta-catenin and Smad signaling to promote myofibroblast formation and pulmonary fibrosis. J. Clin. Invest. 119, 213-224 (2009)

83. Wang, Q. et al. Effect of antibody against integrin alpha4 on bleomycin-induced pulmonary fibrosis in mice Biochem Pharmacol 60, 1949-1958 (2000).

84. Volkert, G. et al. Contribution of the $\alpha 8$ integrin chain to the expression of extracellular matrix components. Cell Commun. Adhes. 21, 89-98 (2014).

85. Kitamura, $\mathrm{H}$. et al. Mouse and human lung fibroblasts regulate dendritic cell trafficking, airway inflammation, and fibrosis through integrin av $\beta 8$-mediated activation of TGF- $\beta$. J. Clin. Invest. 121, 2863-2875 (2011).

86. Popov, Y. et al. Integrin alphavbeta6 is a marker of the progression of biliary and portal liver fibrosis and a novel target for antifibrotic therapies. J. Hepatol 48 453-464 (2008).

87. Henderson, N. C. et al. Targeting of av integrin identifies a core molecular pathway that regulates fibrosis in several organs. Nat. Med. 19, 1617-1624 (2013).

88. Wang, B. et al. Role of alphavbeta6 integrin in acute biliary fibrosis. Hepatology 46, 1404-1412 (2007)

89. Ulmasov, B. et al. An inhibitor of arginine-glycineaspartate-binding integrins reverses fibrosis in a mouse model of nonalcoholic steatohepatitis. Hepatol. Commun. 3, 246-261 (2018).

90. Klinkhammer, B. M., Goldschmeding, R., Floege, J. \& Boor, P. Treatment of renal fibrosis-turning challenges into opportunities. Adv. Chronic Kidney Dis. 24, 117-129 (2017)

91. Hahm, K. et al. Alphav beta6 integrin regulates renal fibrosis and inflammation in Alport mouse. Am. J. Pathol. 170, 110-125 (2007).

92. Chang, Y. et al. Pharmacologic blockade of $\alpha v \beta 1$ integrin ameliorates renal failure and fibrosis in vivo. J. Am. Soc. Nephrol. 28, 1998-2005 (2017).

93. Ma, L. J. et al. Transforming growth factor-betadependent and -independent pathways of induction of tubulointerstitial fibrosis in beta6(-/-) mice. Am. J. Pathol. 163, 1261-1273 (2003).

94. Cox, J. M. et al. Composition and methods for treating chronic kidney disease. US 20190307735 (2019).

95. Zhou, X. et al. An integrin antagonist (MK-0429) decreases proteinuria and renal fibrosis in the ZSF rat diabetic nephropathy model. Pharmacol. Res. Perspect. 5, e00354 (2017)

96. Gerber, E. E. et al. Integrin-modulating therapy prevents fibrosis and autoimmunity in mouse models of scleroderma. Nature 503, 126-130 (2013).

97. Bagnato, G. L. et al. Dual $\alpha \vee \beta 3$ and $\alpha v \beta 5$ blockade attenuates fibrotic and vascular alterations in a murine model of systemic sclerosis. Clin. Sci. 132, 231-242 (2018)

98. Katsumoto, T. R., Violette, S. M. \& Sheppard, D. Blocking TGF $\beta$ via inhibition of the $\alpha \mathrm{v} \beta 6$ integrin: a possible therapy for systemic sclerosis interstitial lung disease. Int. J. Rheumatol. 2011, 208219 (2011).

99. Hamidi, H. \& Ivaska, J. Every step of the way: integrins in cancer progression and metastasis. Nat. Rev. Cancer 18, 533-548 (2018)

100. Seguin, L., Desgrosellier, J. S., Weis, S. M. \& Cheresh, D. A. Integrins and cancer: regulators of cancer stemness, metastasis, and drug resistance. Trends Cell Biol. 25, 234-240 (2015).

101. Nieberler, M. et al. Exploring the role of RGDrecognizing integrins in cancer. Cancers 9, 116 (2017).

102. Bates, R. C. et al. Transcriptional activation of integrin beta6 during the epithelial-mesenchymal transition defines a novel prognostic indicator of aggressive colon carcinoma. J. Clin. Invest. 115, 339-347 (2005)

103. Elayadi, A. N. et al. A peptide selected by biopanning identifies the integrin alphavbeta6 as a prognostic biomarker for nonsmall cell lung cancer. Cancer Res. 67, 5889-5895 (2007)

104. Hazelbag, S. et al. Overexpression of the alpha v beta 6 integrin in cervical squamous cell carcinoma is a prognostic factor for decreased survival. J. Pathol. 212, 316-324 (2007).

105. Zhang, Z. Y. et al. Integrin alphavbeta6 acts as a prognostic indicator in gastric carcinoma. Clin. Oncol. 20, 61-66 (2008)

106. Élez, E. et al. Abituzumab combined with cetuximab plus irinotecan versus cetuximab plus irinotecan alone for patients with KRAS wild-type metastatic colorectal cancer: the randomised phase I/II POSEIDON trial. Ann. Oncol. 26, 132-140 (2015).

107. O'Day, S. et al. CNTO 95 Investigators. A randomised, phase II study of intetumumab, an anti- $\alpha$-integrin mAb, alone and with dacarbazine in stage IV melanoma. Br. J. Cancer 105, 346-352 (2011).
108. Keat, N. et al. A microdose PET study of the safety, immunogenicity, biodistribution, and radiation dosimetry of 18F-FB-A20FMDV2 for imaging the integrin av $\beta 6$. J. Nucl. Med. Technol. 46, 136-143 (2018).

109. Reader, C. S. et al. The integrin $\alpha v \beta 6$ drives pancreatic cancer through diverse mechanisms and represents an effective target for therapy. J. Pathol. 249, 332-342 (2019).

110. Moore, K. M. et al. Therapeutic targeting of integrin av $\beta 6$ in breast cancer. J. Natl Cancer Inst. 106 dju169 (2014)

111. Moore, K. M. et al. Integrin av $\beta 6$-specific therapy for pancreatic cancer developed from foot-and-mouthdisease virus. Theranostics 10, 2930-2942 (2020).

112. Chen, D. S. \& Mellman, I. Oncology meets immunology: the cancer-immunity cycle. Immunity 39 $1-10$ (2013).

113. Pardoll, D. M. The blockade of immune checkpoints in cancer immunotherapy. Nat. Rev. Cancer 12, 252-264 (2012).

114. Akinleye, A. \& Rasool, Z. Immune checkpoint inhibitors of PD-L1 as cancer therapeutics. J. Hematol. Oncol. 12, 92 (2019).

115. Brown, N. F. \& Marshall, J. F. Integrin-mediated TGF $\beta$ activation modulates the tumour microenvironment. Cancers 11, 1221 (2019).

116. Vannini, A. et al. av $\beta 3$-integrin regulates PD-L1 expression and is involved in cancer immune evasion. Proc. Natl Acad. Sci. USA 116, 20141-20150 (2019).

117. Jenkins, R. W., Barbie, D. A. \& Flaherty, K. T. Mechanisms of resistance to immune checkpoint inhibitors. Br. J. Cancer 118, 9-16 (2018).

118. Bagati, A. et al. Integrin $\alpha v \beta 6$-TGF $\beta$-SOX 4 pathway drives immune evasion in triple-negative breast cancer Cancer Cell 39, 54-67.e9 (2021).

119. Takasaka, N. et al. Integrin av $\beta 8$-expressing tumor cells evade host immunity by regulating TGF- $\beta$ activation in immune cells. JCl Insight 3, e122591 (2018).

120. Dodagatta-Marri, E. et al. Integrin $\alpha v \beta 8$ on T cells suppresses anti-tumor immunity in multiple models and is a promising target for tumor immunotherapy. Cell Rep. 36, 109309 (2021).

121. Reszka-Blanco, N. et al. Inhibition of integrin $a v \beta 8$ enhances immune checkpoint induced anti-tumor immunity by acting across immunologic synapse in syngeneic models of breast cancer. Poster 1559. https://investor.morphictx.com/static-files/ cc336336-fe88-4947-a8d9-5afbb5b4691c (2021).

122. Tauriello, D. et al. TGF $\beta$ drives immune evasion in genetically reconstituted colon cancer metastasis Nature 554, 538-543 (2018).

123. Mariathasan, S. et al. TGF $\beta$ attenuates tumour response to PD-L1 blockade by contributing to exclusion of T cells. Nature 554, 544-548 (2018).

124. Hailemichael, Y. et al. Potentiating immune checkpoint blockade therapeutic efficacy using a small molecule activator of integrin cell adhesion receptors [abstr.] Cancer Res. https://doi.org/10.1158/1538-7445. AM2019-5010 (2019).

125. Hood, J. D. et al. Tumor regression by targeted gene delivery to the neovasculature. Science 296, 2404-2407 (2002).

126. Shan, D. et al. RGD-conjugated solid lipid nanoparticles inhibit adhesion and invasion of av $\beta 3$ integrin-overexpressing breast cancer cells. Drug Deliv. Transl. Res. 5, 15-26 (2015).

127. Zhang, T. et al. Dual-targeted hybrid nanoparticles of synergistic drugs for treating lung metastases of triple negative breast cancer in mice. Acta Pharmacol. Sin. 38, 835-847 (2017)

128. Gajbhiye, K. R., Gajbhiye, V., Siddiqui, I. A. \& Gajbhiye, J. M. cRGD functionalised nanocarriers for targeted delivery of bioactives. J. Drug Target. 27 , 111-124 (2019).

129. Patnaik, A. et al. A phase 1 study of SGN-B6A, an antibody-drug conjugate targeting integrin beta- 6 , in patients with advanced solid tumors (SGNB6A-001, Trial in Progress). J. Clin. Oncol. 39 (15_Suppl.), TPS3144 (2021)

130. Maginnis, M. S. Virus-receptor interactions: the key to cellular invasion. J. Mol. Biol. 430, 2590-2611 (2018)

131. Hussein, H. A. et al. Beyond RGD: virus interactions with integrins. Arch. Virol. 160, 2669-2681 (2015).

132. Wang, S. et al. Integrin $\alpha v \beta 5$ internalizes Zika virus during neural stem cells infection and provides a promising target for antiviral therapy. Cell Rep. 30 , 969-983.e4 (2020). 
133. Guerrero, C. A. et al. Integrin alpha(v)beta(3) mediates rotavirus cell entry. Proc. Natl Acad. Sci. USA 97 14644-14649 (2000).

134. Schornberg, K. L. et al. Alpha5beta1-integrin controls ebolavirus entry by regulating endosomal cathepsins. Proc. Natl Acad. Sci. USA 106, 8003-8008 (2009).

135. Kotecha, A. et al. Rules of engagement between av $\beta 6$ integrin and foot-and-mouth disease virus. Nat. Commun. 8, 15408 (2017).

136. Sigrist, C. J., Bridge, A. \& Le Mercier, P. A potential role for integrins in host cell entry by SARS-CoV-2. Antivir. Res. 177, 104759 (2020).

137. Makowski, L., Olson-Sidford, W. \& W-Weisel, J. Biological and clinical consequences of integrin binding via a rogue RGD motif in the SARS CoV-2 spike protein. Viruses 13, E146 (2021).

138. Beddingfield, B. J. et al. The integrin binding peptide, ATN-161, as a novel therapy for SARS-CoV-2 infection. JACC Basic Transl. Sci. 6, 1-8 (2021).

139. Garbaccio, R. M. \& Parmee, E. R. The impact of chemical probes in drug discovery: a pharmaceutical industry perspective. Cell Chem. Biol. 23, 10-17 (2016)

140. Lipinski, C. A., Lombardo, F., Dominy, B. W. \& Feeney, P. J. Experimental and computational approaches to estimate solubility and permeability in drug discovery and development settings. Adv. Drug Deliv. Rev. 46, 3-26 (2001)

141. Lipinski, C. A. Lead- and drug-like compounds: the rule-of-five revolution. Drug Discov. Today Technol. 1, 337-341 (2004).

142. Cumming, J. G., Davis, A. M., Muresan, S Haeberlein, M. \& Chen, H. Chemical predictive modelling to improve compound quality. Nat. Rev. Drug Discov. 12, 948-962 (2013).

143. Egbert, M., Whitty, A., Keserü, G. M. \& Vajda, S. Why some targets benefit from beyond rule of five drugs. J. Med. Chem. 62, 10005-10025 (2019).

144. DeGoey, D. A., Chen, H. J., Cox, P. B. \& Wendt, M. D. Beyond the Rule of 5: lessons learned from AbbVie's drugs and compound collection. J. Med. Chem. 61 2636-2651 (2018)

145. Veber, D. F. et al. Molecular properties that influence the oral bioavailability of drug candidates. J. Med Chem. 45, 2615-2623 (2002)

146. Nicholson, N. S. et al. SC-54684A: an orally active inhibitor of platelet aggregation. Circulation 91 403-410 (1995)

147. Nicholson, N. S. et al. Orbofiban: an orally active GPIIb/IIla platelet receptor antagonist. Med. Res. Rev. 21, 211-226 (2001)

148. Turaga R C et al. Rational design of a protein that binds integrin $\alpha \mathrm{v} \beta 3$ outside the ligand binding site. Nat. Commun. 7, 11675 (2016)

149. Miller, L. M., Pritchard, J. M., Macdonald, S. Jamieson, C. \& Watson, A. Emergence of small-molecule non-RGD-mimetic inhibitors for RGD integrins. J. Med. Chem. 60, 3241-325 (2017)

150. Hatley, R. et al. The design of potent, selective and drug-like RGD av $\beta 1$ small-molecule inhibitors derived from non-RGD a $4 \beta 1$ antagonists. ChemMedChem 14, 1315-1320 (2019)

151. Zheng, Y. \& Leftheris, K. Insights into protein-ligand interactions in integrin complexes: advances in structure determinations. J. Med. Chem. 63, 5675-5696 (2020)

152. Xiong, J. P. et al. Crystal structure of the extracellular segment of integrin alpha Vbeta3. Science 294 339-345 (2001)

153. Dong, X. et al. Force interacts with macromolecular structure in activation of TGF- $\beta$. Nature 542, 55-59 (2017)

154. Procopiou, P. A. et al. Discovery of (S)-3-(3-(3 5-dimethyl-1 H-pyrazol-1-yl)phenyl)-4-((R)-3(2-(5,6,7,8-tetrahydro-1,8-naphthyridin-2-yl)ethyl) pyrrolidin-1-yl)butanoic acid, a nonpeptidic av $\beta 6$ integrin inhibitor for the inhaled treatment of idiopathic pulmonary fibrosis. J. Med. Chem. 61, 8417-8443 (2018)

155. Sorge, J. L., Wagstaff, J. L., Rowe, M. L., Williamson, R. A. \& Howard, M. J. Q2DSTD NMR deciphers epitope-mapping variability for peptide recognition of integrin $\alpha \vee \beta 6$. Org. Biomol. Chem. 13 8001-8007 (2015)

156. Claasen, B., Axmann, M., Meinecke, R. \& Meyer, B. Direct observation of ligand binding to membrane proteins in living cells by a saturation transfer double difference (STDD) NMR spectroscopy method shows a significantly higher affinity of integrin alpha(llb)beta3 in native platelets than in liposomes. J. Am. Chem. Soc. 127, 916-919 (2005).
157. Vasile, F. et al. Insight to the binding mode of triazole RGD-peptidomimetics to integrin-rich cancer cells by NMR and molecular modeling. Bioorg. Med. Chem. 24, 989-994 (2016)

158. Di Leva, F. S. et al. From a helix to a small cycle: metadynamics-inspired $\alpha \vee \beta 6$ integrin selective ligands. Angew. Chem. Int. Ed. Engl. 57, 14645-14649 (2018).

159. Nanthakumar, C. B., Hatley, R. J. D. \& Slack, R. J. in Anti-fibrotic Drug Discovery (eds Brenneman, J. \& lyer, M. R.) ch. 2, 37-75 (Royal Society of Chemistry, 2020)

160. Reichart, F. et al. Selective targeting of integrin $a v \beta 8$ by a highly active cyclic peptide. J. Med. Chem. 62, 2024-2037 (2019).

161. Lippa, R. A. et al. Discovery of the first potent and selective $\alpha v \beta 5$ integrin inhibitor based on an amidecontaining core. Eur. J. Med. Chem. 208, 112719 (2020).

162. Barrett, T. N. et al. Profile of a highly selective quaternized pyrrolidine betaine $\alpha v \beta 6$ integrin inhibitor-(3S)-3-(3-(3,5-dimethyl-1 $H$-pyrazol-1-yl) phenyl)-4-((1S and $1 R, 3 R)-1$-methyl-3- $(2-(5,6,7$ 8-tetrahydro-1,8-naphthyridin-2-yl)ethyl)pyrrolidin1-ium-1-yl)butanoate synthesized by stereoselective methylation. J. Med. Chem. 62, 7543-7556 (2019).

163. Anderson, N. A. et al. Discovery of an orally bioavailable pan $\alpha v$ integrin inhibitor for idiopathic pulmonary fibrosis. J. Med. Chem. 62, 8796-8808 (2019).

164. Hagmann, W. K. et al. The discovery of sulfonylated dipeptides as potent VLA-4 antagonists. Bioorg. Med. Chem. Lett. 11, 2709-2713 (2001).

165. Choi, S. et al. Small molecule inhibitors of integrin alpha2beta1. J. Med. Chem. 50, 5457-5462 (2007).

166. Reed, N. I. et al. Exploring $N$-arylsulfonyl-I-proline scaffold as a platform for potent and selective $\alpha v \beta 1$ integrin inhibitors. ACS Med. Chem. Lett. 7, 902-907 (2016).

167. Kapp, T. G. et al. A comprehensive evaluation of the activity and selectivity profile of ligands for RGDbinding integrins. Sci. Rep. 7, 39805 (2017).

168. Cha, J. et al. Amino acid compounds and methods of use. Patent WO2019173653 (2019)

169. Anderson, N. A. et al. Novel compounds. Patent WO2016046226 (2016)

170. Ruminski, P. G. \& Griggs, D. W. Meta-azacyclic amino benzoic acid derivatives as pan integrin antagonists. Patent WO2017117538 (2017).

171. Thompson, J. Joint RSC CICAG-BMCS Meeting, Sygnature Discovery, BioCity, Nottingham, UK. Investigating the Chameleonic Properties of $\alpha V \beta 6$ Integrin Antagonists for the Treatment of IPF. https:// www.rsc.org/images/CICAG_Newsletter_Winter 2019-20_tcm 18-252021.pdf (2019)

172. Kuhn, B., Mohr, P. \& Stahl, M. Intramolecular hydrogen bonding in medicinal chemistry. J. Med. Chem. 53, 2601-2611 (2010)

173. Maher, T. M. et al. A positron emission tomography imaging study to confirm target engagement in the lungs of patients with idiopathic pulmonary fibrosis following a single dose of a novel inhaled $\alpha \mathrm{v} \beta 6$ integrin inhibitor. Respir. Res. 21, 75 (2020)

174. Fierce Biotech. Biogen axes phase 2 study lung scarring med due to safety concerns. https://www. fiercebiotech.com/biotech/biogen-axes-phase-2-studylung-scarring-med-due-to-safety-concerns (2017).

175. Lo, D. J et al. Inhibition of $\alpha v \beta 6$ promotes acute renal allograft rejection in nonhuman primates. $\mathrm{Am}$. $\mathrm{J}$. Transplant. 13, 3085-3093 (2013).

176. Tam, S. H., Sassoli, P. M., Jordan, R. E. \& Nakada, M. T. Abciximab (ReoPro, chimeric 7E3 Fab) demonstrates equivalent affinity and functional blockade of glycoprotein Ilb/IIla and alpha(v)beta3 integrins. Circulation 98, 1085-1091 (1998).

177. Raghu, G. et al. Randomized, Double-Blind, PlaceboControlled, Multiple Dose, Dose-Escalation Study of BG00011 (Formerly STX-100) in Patients with Idiopathic Pulmonary Fibrosis (IPF). D14. ILD: Clinical Research. https://doi.org/10.1164/ajrccm conference.2018.197.1_MeetingAbstracts.A7785 (2018).

178. Eberlein, C. et al. A human monoclonal antibody 264RAD targeting $\alpha v \beta 6$ integrin reduces tumour growth and metastasis, and modulates key biomarkers in vivo. Oncogene 32, 4406-4416 (2013).

179. Prinz, F., Schlange, T. \& Asadullah, K. Believe it or not: how much can we rely on published data on potential drug targets? Nat. Rev. Drug Discov. 10, 712 (2011).

180. Mercer, P. F. et al. Exploration of a potent PI3 kinase/ mTOR inhibitor as a novel anti-fibrotic agent in IPF. Thorax 71, 701-711 (2016).
181. Paish, H. L. et al. A bioreactor technology for modeling fibrosis in human and rodent precision-cut liver slices. Hepatology 70, 1377-1391 (2019).

182. Nelson, M. R. et al. The support of human genetic evidence for approved drug indications. Nat. Genet. 47, 856-860 (2015).

183. Allen, R J J et al. Genetic variants associated with susceptibility to idiopathic pulmonary fibrosis in people of European ancestry: a genome-wide association study. Lancet Respir. Med. 5, 869-880 (2017)

184. Organ, L., Porte, J., John, A. \& Jenkins, R. G Investigating the role of AKAP13 in epithelial cells on TGF- $\beta$ activation. Thorax 74, S91 (2021).

185. Hamilton R. J. (Ed. in Chief) Tarascon Pocket Pharmacopoeia (Jones \& Bartlett Learning, 2020)

186. Kossen, K. et al. IDL-2965: a selective, highly-potent, oral integrin antagonist for IPF. Eur. Respir. J. 54 PA5374 (2019).

187. Kossen, K. et al. IDL-2965: a selective, highly potent, clinical-stage integrin antagonist for the treatment of NASH. Poster. https://www. postersessiononline. eu/173580348_eu/congresos/NAFLD2019/ aula/-P05_17_NAFLD2019.pdf (2019).

188. Chu, F. M. et al. A phase 1, multicenter, open-label study of the safety of two dose levels of a human monoclonal antibody to human $\alpha(v)$ integrins, intetumumab, in combination with docetaxel and prednisone in patients with castrate-resistant metastatic prostate cancer. Invest. New Drugs 29, 674-679 (2011)

189. Heidenreich, A. et al. A randomized, double-blind, multicenter, phase 2 study of a human monoclonal antibody to human av integrins (intetumumab) in combination with docetaxel and prednisone for the first-line treatment of patients with metastatic castration-resistant prostate cancer. Ann. Oncol. 24 329-336 (2013).

190. Maden, C. H. et al. Safety, tolerability and pharmacokinetics of GSK3008348, a novel integrin av 36 inhibitor, in healthy participants. Eur. J. Clin. Pharmacol. 74, 701-709 (2018).

191. Rosenthal, M. A. et al. Evaluation of the safety, pharmacokinetics and treatment effects of an alpha(v) beta(3) integrin inhibitor on bone turnover and disease activity in men with hormone-refractory prostate cancer and bone metastases. Asia Pac. J. Clin. Oncol. 6, 42-48 (2010).

192. Roche provides update on phase III studies of etrolizumab in people with moderately to severely active ulcerative colitis. https://www.roche.com/ investors/updates/inv-update-2020-08-10.htm (2021).

193. Vascular Pharma. VPI-2690B. http://www. vascularpharma.com/science/vpi-2690b (2021).

194. Oxurion NV - Expert Presentation of Positive Topline Data from a Phase 1 Study evaluating THR-687 for the treatment of DME, at Angiogenesis, Exudation, and Degeneration 2020 Conference. https://www. oxurion.com/content/oxurion-nv-expertpresentation-positive-topline-data-phase-1-studyevaluating-thr-687 (2020)

195. SciFluor Announces Positive Top-Line Results of Phase 1/2 Study of SF0166 Eye Drops to Treat Wet Age-Related Macular Degeneration. https://www. businesswire.com/news/home/20171218005625/ en/SciFluor-Announces-Positive-Top-Line-ResultsPhase-12 (2019)

196. Maturi, R. et al. Safety and efficacy of risuteganib in intermediate non-exudative age-related macular degeneration. Invest. Ophthalmol. Vis. Sci. 61, 1944 (2020).

197. Turner, S. et al. Late Breaking Abstract - PK/PD assessment of an oral, selective $\alpha \mathrm{V} \beta 6 / \alpha \mathrm{V} \beta 1$ integrin dual antagonist, PLN-74809, for the treatment of idiopathic pulmonary fibrosis. Eur. Respir. J. 54, PA1298 (2019).

198. Dalmas Wilk, D. A., Scicchitano, M. S. \& Morel, D. In vitro investigation of integrin-receptor antagonistinduced vascular toxicity in the mouse. Toxicol. Vitr. 27, 272-281 (2013)

199. Hawiger, J., Kloczewiak, M., Bednarek, M. A. \& Timmons, S. Platelet receptor recognition domains on the alpha chain of human fibrinogen: structurefunction analysis. Biochemistry 28, 2909-2914 (1989).

200. Chew, D. P., Bhatt, D. L., Sapp, S. \& Topol, E. J. Increased mortality with oral platelet glycoprotein IIb/IIla antagonists: a meta-analysis of phase II multicenter randomized trials. Circulation 103 201-206 (2001) 
201. Yednock, T. A. et al. Prevention of experimental autoimmune encephalomyelitis by antibodies against alpha 4 beta 1 integrin. Nature 356, 63-66 (1992).

202. Sandborn, W. J. et al. Efficacy and safety of abrilumab in a randomized, placebo-controlled trial for moderate-to-severe ulcerative colitis. Gastroenterology 156, 946-957.e18 (2019).

203. Fukase, H., Kajioka, T., Oikawa, I., Ikeda, N. \& Furuie, H. AJM300, a novel oral antagonist of a4-integrin, sustains an increase in circulating lymphocytes: a randomised controlled trial in healthy male subjects. Br. J. Clin. Pharmacol. 86, 591-600 (2020).

204. Tang, M. T. et al. Nonclinical and clinical pharmacology, pharmacokinestics and pharmacodynamics of etrolizumab, an anti- $\beta 7$ integrin therapy for inflammatory bowel disease. Aliment. Pharmacol. Ther. 47, 1440-1452 (2018).

205. Vermeire, S. et al. Etrolizumab as induction therapy for ulcerative colitis: a randomised, controlled, phase 2 trial. Lancet 384, 309-318 (2014).

206. Margadant, C. \& Sonnenberg, A. Integrin-TGF-beta crosstalk in fibrosis, cancer and wound healing. EMBO Rep. 11, 97-105 (2010).

207. Sheppard, D. The role of integrins in pulmonary fibrosis. Eur. Respir. Rev. 17, 157-162 (2008)

208. Mu, D. et al. The integrin alpha(v)beta8 mediates epithelial homeostasis through MT1-MMP-dependent activation of TGF-beta1. J. Cell Biol. 157, 493-507 (2002).
209. Wipff, P. J. \& Hinz, B. Integrins and the activation of latent transforming growth factor beta 1 - an intimate relationship. Eur. J. Cell Biol. 87, 601-615 (2008).

210. Thannickal, V. J. et al. Myofibroblast differentiation by transforming growth factor-beta 1 is dependent on cell adhesion and integrin signaling via focal adhesion kinase. J. Biol. Chem. 278, 12384-12389 (2003).

Acknowledgements

The authors thank Megan Cully for editorial support.

\section{Author contributions}

R.J.S., J.A.R and S.J.F.M. and R.J.D.H. researched data, discussed the content, wrote the article and edited/reviewed the manuscript before submission. R.G.J. edited/reviewed the manuscript before submission.

\section{Competing interests}

R.J.D.H. and S.J.F.M. hold GSK shares and are applicants on GSK integrin patents. R.J.S. and J.A.R. hold GSK shares and are currently Galecto, Inc. employees and shareholders. R.G.J. reports grants from GlaxoSmithKline, grants and personal fees from Pliant Therapeutics, grants from Biogen during the conduct of the study; personal fees from Galapagos, other from Galecto, personal fees and other from GlaxoSmithKline, personal fees and other from AstraZeneca, personal fees from Boehringer Ingelheim, personal fees from Pliant, personal fees from Bristol-Myers Squibb, personal fees from Chiesi, personal fees from Roche/Promedior, personal fees and other from RedX, other from NuMedii, other from Nordic Biosciences, personal fees from Veracyte, personal fees from PatientMPower, personal fees from Resolution Therapeutics, personal fees from Vicore, outside the submitted work; he is supported by a National Institute of Health Research Professorship (NIHR ref: RP-2017-08-ST2-014). $\mathrm{He}$ is a trustee for Action for Pulmonary Fibrosis.

\section{Peer review information}

Nature Reviews Drug Discovery thanks Scott Turner, Zhiyuan Zhong and the other, anonymous, reviewer(s) for their contribution to the peer review of this work.

\section{Publisher's note}

Springer Nature remains neutral with regard to jurisdictional claims in published maps and institutional affiliations.

\section{Supplementary information}

The online version contains supplementary material available at https://doi.org/10.1038/s41573-021-00284-4.

\section{RELATED LINKS}

Eurofins kinase screening: https://www.

eurofinsdiscoveryservices.com/services/in-vitro-assays/

kinases/screening-profiling-services/

MRC PPU kinase screening: http://www.kinase-screen.mrc.

ac.uk/

(c) Springer Nature Limited 2021 